\title{
Perinatal Fentanyl Exposure Leads to Long-Lasting Impairments in Somatosensory Circuit Function and Behavior
}

\author{
${ }^{\circledR}$ Jason B. Alipio, Catherine Haga, ${ }^{\circledR}$ Megan E. Fox, Keiko Arakawa, Rakshita Balaji, Nathan Cramer, \\ (ㄱ) Mary Kay Lobo, and ${ }^{(1)}$ Asaf Keller \\ Department of Anatomy and Neurobiology, Program in Neuroscience, University of Maryland School of Medicine, Baltimore, Maryland 21201
}

One consequence of the opioid epidemic are lasting neurodevelopmental sequelae afflicting adolescents exposed to opioids in the womb. A translationally relevant and developmentally accurate preclinical model is needed to understand the behavioral, circuit, network, and molecular abnormalities resulting from this exposure. By employing a novel preclinical model of perinatal fentanyl exposure, our data reveal that fentanyl has several dose-dependent, developmental consequences to somatosensory function and behavior. Newborn male and female mice exhibit signs of withdrawal and sensory-related deficits that extend at least to adolescence. As fentanyl exposure does not affect dams' health or maternal behavior, these effects result from the direct actions of perinatal fentanyl on the pups' developing brain. At adolescence, exposed mice exhibit reduced adaptation to sensory stimuli, and a corresponding impairment in primary somatosensory (S1) function. In vitro electrophysiology demonstrates a long-lasting reduction in S1 synaptic excitation, evidenced by decreases in release probability, NMDA receptor-mediated postsynaptic currents, and frequency of miniature excitatory postsynaptic currents (mEPSCs), as well as increased frequency of miniature inhibitory postsynaptic currents (mIPSCs). In contrast, anterior cingulate cortical neurons exhibit an opposite phenotype, with increased synaptic excitation. Consistent with these changes, electrocorticograms (ECoGs) reveal suppressed ketamine-evoked $\gamma$ oscillations. Morphologic analysis of S1 pyramidal neurons indicate reduced dendritic complexity, dendritic length, and soma size. Further, exposed mice exhibited abnormal cortical mRNA expression of key receptors involved in synaptic transmission and neuronal growth and development, changes that were consistent with the electrophysiological and morphologic changes. These findings demonstrate the lasting sequelae of perinatal fentanyl exposure on sensory processing and function.

Key words: Developmental Biology; opioid; somatosensory; thalamocortical

Significance Statement

This is the first study to show that exposure to fentanyl in the womb results in behavioral, circuitry, and synaptic effects that last at least to adolescence. We also show, for the first time, that this exposure has different, lasting effects on synapses in different cortical areas.

\section{Introduction}

Opioid use dependence and addiction have increased to epidemic proportions, leading to substantial financial and societal health burdens in the United States (Ryan, 2018). While opioid use dependence is highest in the United States, globally, the

Received Sep. 21, 2020; revised Dec. 7, 2020; accepted Dec. 30, 2020.

Author contributions: J.B.A., M.E.F., M.K.L., and A.K. designed research; J.B.A., C.H., M.E.F., K.A., R.B., N.C., and A.K. performed research; J.B.A., C.H., M.E.F., K.A., R.B., N.C., M.K.L., and A.K. analyzed data; J.B.A. and A.K. wrote the paper.

This work was supported by the Opioid Use Disorders Initiative, MPowering The State, from the State of Maryland. Support was provided also by NIH/NIDA R01 DA038613 (to M.K.L.) and K99 DA050575 (to M.E.F.). We thank Lace M. Riggs for providing valuable comments on the manuscript.

The authors declare no competing financial interests.

Correspondence should be addressed to Asaf Keller at akeller@som.umaryland.edu.

https://doi.org/10.1523/JNEUROSCI.2470-20.2020

Copyright $\odot 2021$ the authors prevalence of opioid use disorders has increased by $47 \%$ from 1990 to 2016, with women representing one-third of the increase (GBD 2016 Alcohol and Drug Use Collaborators, 2018). In the United States, $>20 \%$ of pregnant women enrolled in Medicaid are prescribed opioids. In recent years, there was a 14-fold increase in the proportion of pregnant women self-reporting opioid use. As a result of these trends, the incidence of infants born to opioid-using mothers has increased $>400 \%$ between 2000 and 2012 (Haight et al., 2018; Winkelman et al., 2018; Honein et al., 2019). Not only does opioid use increase the risk of miscarriage, premature birth, and stillbirth (Whiteman et al., 2014), newborns exposed to opioids in utero may develop neonatal opioid withdrawal syndrome (NOWS), lower birth weight, smaller head circumference, and a higher risk of sudden infant death syndrome (Kandall et al., 1976; McPherson et al., 2015). 
Current pharmacologic treatment options for newborns with NOWS include opioid formulations of morphine, methadone, and buprenorphine (Sutter et al., 2014). While opioid therapy for newborns with NOWS improves acute withdrawal symptoms, such treatment further increases their exposure to these substances. Of particular concern is the fact that neurodevelopmental deficits may be permanent, as some have been found to persist at least to early adolescence (Lee et al., 2020).

There is a higher risk for sensory-related deficits in adolescents who were exposed to opioids prenatally (Ornoy et al., 2001; Kivisto et al., 2015). Perinatal opioid exposure also increases the risk for other disorders that are characterized by sensory processing deficits, such as attention deficit and autism spectrum disorders (Ayres, 1964; Rogers and Ozonoff, 2005; Robertson and Baron-Cohen, 2017; Balasco et al., 2019; Kilroy et al., 2019), which are also increased by perinatal opioid exposure (Ornoy, 2003; Hunt et al., 2008; Rubenstein et al., 2019).

Nearly all studies of perinatal exposure have focused on the naturally occurring opioid, morphine. However, the number of encounters with synthetic opioids, primarily fentanyl, has increased 300\% since 2014 (O’Donnell et al., 2017; Jannetto et al., 2019). Fentanyl is 50-100 times more potent than morphine and is responsible for the majority of opioid-related overdose deaths (Volpe et al., 2011; Spencer et al., 2019). Understanding the effects that synthetic opioids have on the developmental trajectory of offspring is critically needed to develop effective treatment and prevention plans. To investigate the persistent neurobiological behavioral, circuit, network, and molecular abnormalities following perinatal fentanyl exposure, we developed a mouse model of such exposure, in which pregnant mouse dams are exposed to fentanyl (Alipio et al., 2020). We showed that newborn pups exhibit signs of spontaneous somatic withdrawal. During adolescence, fentanyl-exposed mice displayed abnormal affective-like behavior. By adulthood, fentanyl-exposed mice exhibited deficits in auditory processing.

In the present study, we further validate this model by determining the effects of different doses of fentanyl on maternal care and health. We then use this model to study the consequences of perinatal fentanyl exposure on sensory behaviors during adolescence, as well as the synaptic mechanisms that subserve them. We focus on the primary somatosensory cortex (S1) and anterior cingulate cortex (ACC), as they play key roles in sensory processing and integration (Mountcastle, 1998).

\section{Materials and Methods}

Animals

All procedures adhered to the Guide for the Care and Use of Laboratory Animals and approved by the Institutional Animal Care and Use Committee at the University of Maryland School of Medicine. Male and female C57BL/6J mice were used and bred in our temperature and humidity-controlled vivarium. Separate cohorts of animals were used for each behavioral test to prevent possible crossover effects between tests. When copulatory plugs were identified, we removed the sires, and added fentanyl or vehicle control to the water hydration pouches. Offspring were weaned at postnatal day (PD)21 and housed two to five per cage in single-sex groups. Food and water were available ad libitum, and lights were maintained on a 12/12 h light/dark cycle.

\section{Statistical analyses}

Statistical tests were conducted using Prism 8 (GraphPad) and sample size was determined using G*Power software suite (HeinrichHeine, Universität Düsseldorf). Detailed statistical data are listed in Table 1 . If there was no statistically significant sex difference or exposure/sex interaction, we grouped animals and analyzed according to exposure conditions, per NIH recommendations for studying sex differences. Parametric tests were used when appropriate assumptions were met, otherwise, nonparametric tests were used. Partial $\eta^{2}$ were used to calculate effect size, and Cohen's $d$, Glass' $\delta$, or Hedges' $g$ were used for two group comparisons and selected based on whether parametric assumptions were met. All experimenters were blind to treatment conditions throughout data collection, scoring, and analysis.

\section{Fentanyl citrate}

We used 1,10 , or $100 \mu \mathrm{g} / \mathrm{ml}$ fentanyl citrate (calculated as free base) in $2 \%(\mathrm{w} / \mathrm{v})$ saccharin, or $2 \%$ saccharin (vehicle control) in the water hydration pouches, which were replenished weekly until litters were weaned.

\section{Maternal care behavior}

We assessed maternal behavior as previously described (Alipio et al., 2020). We conducted daily observation sessions of pregnant dams ( $n=9-10$ dams per group) in the vivarium from PD1-PD7, between 9 and 10:30 A.M., and between 2 and 3 P.M. We scan sampled each dam in real time, once a minute for $30 \mathrm{~min}$, yielding 30 scans per session; two sessions per day for $7 \mathrm{~d}$ yielded a total of 420 scans per dam. We used ethological parameters for assessing in and out of nest care-related behaviors, which comprised of: "licking/grooming," "active nursing," "passive nursing," and "nest building." Additionally, "self-grooming" and "eating/drinking" were taken as measures of dam self-maintenance whereas "pups out of nest" and "climbing/digging" were taken as measures of neglectful behavior.

\section{Pup retrieval test}

On PD7, we briefly removed the dam from the home cage and disturbed the nesting material, distributing it throughout the cage $(n=9-11$ dams per group, with a minimum of 4 pups in the litter). We then placed two pups in the corners away from the nest end of the home cage. Then, we reintroduced the dam and measured the latency to sniff a pup, retrieve each of the pups, start nest building, and crouch over pups. We terminated the test if a dam did not complete the task within $15 \mathrm{~min}$, resulting in a latency of $900 \mathrm{~s}$ for any behaviors not observed during that time frame.

\section{Spontaneous somatic withdrawal behavior}

We tested mice $24 \mathrm{~h}$ after cessation of drug effect on PD22 $(n=8-11$ mice per group). We first habituated mice to the testing room for $1 \mathrm{~h}$ and scored behaviors in real time in 5-min time bins for a 15 min observation period. Spontaneous somatic withdrawal signs were scored using a modified rating scale (Schulteis et al., 1999). Counted signs included escape jumps and wet dog shakes. Escape jumps equaling 2-4 were assigned 1 point, 5-9 were assigned 2 points, and 10 or more were assigned 3 points. Wet dog shakes equaling 1-2 were assigned 2 points, and 3 or more were assigned 4 points. All other presence signs were assigned 2 points and consisted of 10 distinct behaviors, including persistent trembling, abnormal postures, abnormal gait, paw tremors, teeth chattering, penile erection/ genital grooming, excessive eye blinking, ptosis (orbital tightening), swallowing movements, and diarrhea. Counted and presence scores were summed from all three of the 5-min time bins to compute the global withdrawal score.

\section{Sensory threshold and adaptation}

To assess tactile sensitivity, we habituated mice $(n=10-12$ mice per group) to an elevated clear Plexiglas box with a mesh bottom for $10 \mathrm{~min}$. We applied von Frey filaments of increasing forces to the plantar surface of the hind paw. The filament was applied to the same paw throughout the test. We used the up-down method to determine withdrawal threshold (Dixon, 1965; Chaplan et al., 1994; Deuis et al., 2017). To assess sensory adaptation, we applied a von Frey filament above threshold to the plantar surface of the hind paw, opposite to the hindpaw used during tactile sensitivity testing. The filament was applied once every $30 \mathrm{~s}$ until the animal stopped responding.

\section{In vitro slice electrophysiology}

We used a modified slice collection method (Ting et al., 2014). We anesthetized adolescent mice (PD35-PD45; see Results for sample size used 
Table 1. mRNA expression of receptors involved in synaptic transmission

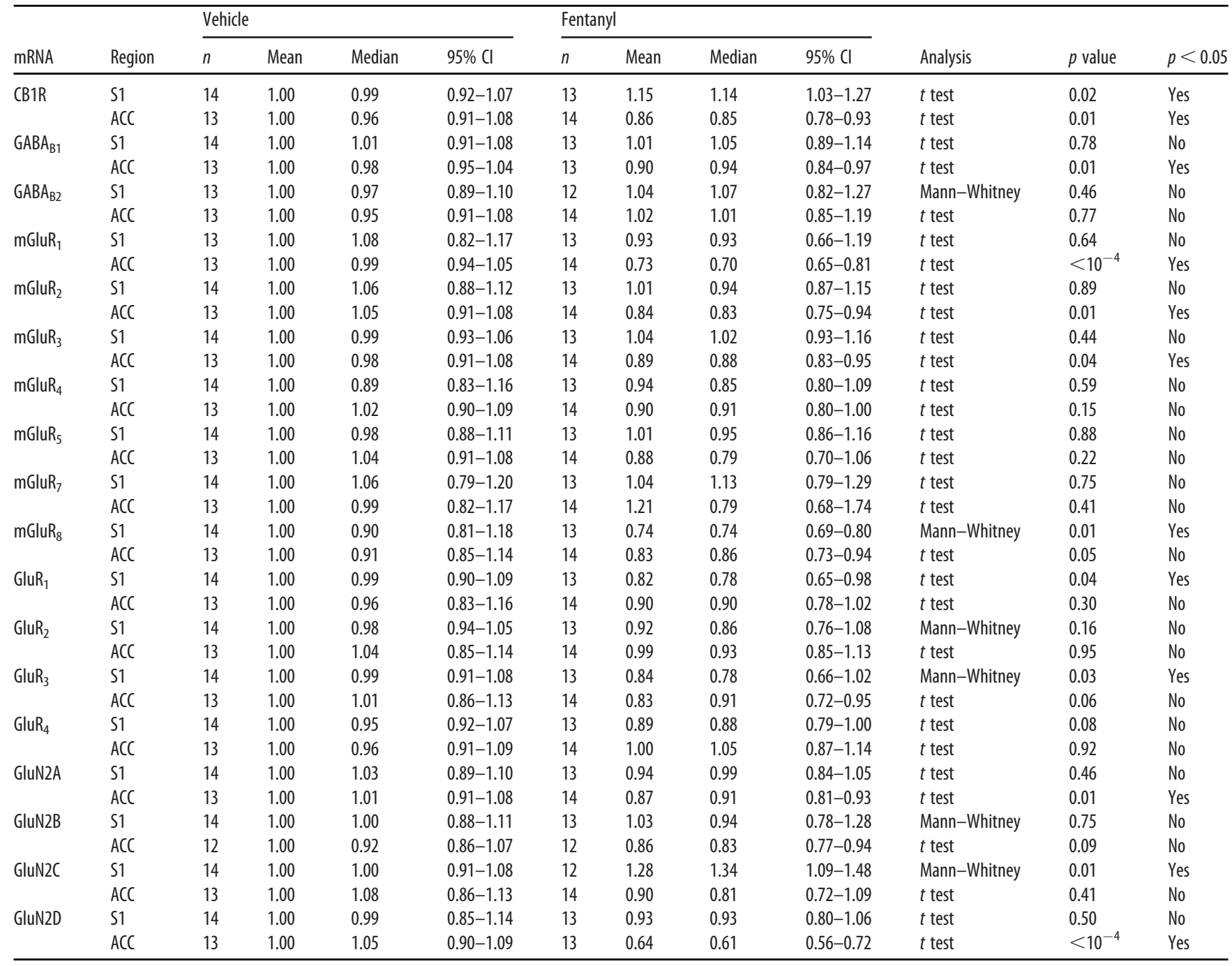

in each experiment) with ketamine/xylazine, removed their brains, and prepared coronal slices $(300 \mu \mathrm{m}$ thick) containing the S1 or ACC. For recordings, we placed slices in a submersion chamber and continually perfused $(2 \mathrm{ml} / \mathrm{min})$ with artificial cerebrospinal fluid (ACSF) containing the following: $119 \mathrm{~mm} \mathrm{NaCl}, 2.5 \mathrm{~mm} \mathrm{KCl}, 1.2 \mathrm{~mm}$ $\mathrm{NaH}_{2} \mathrm{PO}_{4}, 2.4 \mathrm{~mm} \mathrm{NaHCO} 3,12.5 \mathrm{~mm}$ glucose, $2 \mathrm{~mm} \mathrm{MgSO} \cdot 7 \mathrm{H} 2 \mathrm{O}$, and $2 \mathrm{~mm} \mathrm{CaCl}_{2} \cdot 2 \mathrm{H} 2 \mathrm{O}$. Solutions were saturated with carbogen (95\% $\mathrm{O}_{2}$ and $95 \% \mathrm{CO}_{2}$ ) throughout use.

We obtained whole-cell patch-clamp recordings, in voltage-clamp mode $(-70 \mathrm{mV})$, through pipettes containing the following: $130 \mathrm{~mm}$ cesium methanesulfonate, $10 \mathrm{~mm}$ HEPES, $1 \mathrm{~mm}$ magnesium chloride, 2.5 mm ATP-Mg, 0.5 mm EGTA, 0.2 mm GTP-Tris, 5 mm QX-314, and 2\% biocytin. In S1 and ACC, we recorded from layer 5 neurons. For miniature postsynaptic current recordings, tetrodotoxin $(1 \mu \mathrm{M})$ was included in the ACSF. All electrically evoked current responses were recorded at 1.5 times threshold, the minimum stimulation required to produce a current response. We positioned the stimulating electrode below the recorded neuron, in layer 6 . To isolate EPSCs, gabazine $(1 \mu \mathrm{M})$ was included in the ACSF. To isolate IPSCs, 6-cyano-7-nitroquinoxaline-2,3dione (CNQX; $20 \mu \mathrm{M})$ and DL-2-amino-5-phosphonopentanoic acid (APV; $50 \mu \mathrm{M}$ ) was included in the ACSF. The $N$-methyl-D-aspartate receptor (NMDAR)-mediated component of the EPSC was pharmacologically isolated by including CNQX $(20 \mu \mathrm{M})$ in the ACSF and by voltage clamping at $40 \mathrm{mV}$. Impedance of patch electrodes was 4-6 M $\Omega$. Series resistance $<40 \mathrm{M} \Omega$ was monitored throughout the recording, and recordings were discarded if series resistance changed by $>20 \%$. All recordings were obtained at room temperature.
In vivo electrocorticogram (ECoG) recordings

We anesthetized mice (PD30; see Results for sample size used in each experiment) with ketamine/xylazine and subcutaneously implanted a radiotelemetry transmitter (ETA-F10, Data Sciences International) with its leads implanted over the dura above $\mathrm{S} 1(-1.5 \mathrm{~mm}$ from bregma) and the cerebellum $(-6.4 \mathrm{~mm}$ from bregma). Mice were allowed $10 \mathrm{~d}$ to recover from surgery. Mice were acclimated to the behavior testing room for $1 \mathrm{~h}$ before ECoG recordings. ECoGs were recorded with Dataquest A.R.T. acquisition system (Data Sciences International) with cortical ECoG recordings referenced to the cerebellum. Baseline 10-min ECoG recordings were followed by an intraperitoneal injection of vehicle saline or $10 \mathrm{mg} / \mathrm{kg}$ ketamine, and $50 \mathrm{~min}$ of postinjections recordings. Each mouse was injected with either ketamine or saline on consecutive days, with the order counterbalanced between animals. We analyzed ECoG recordings with custom-written MATLAB scripts (version 2019a, MathWorks) and the mtspecgramc routine in the Chronux Toolbox (http://chronux.org; Bokil et al., 2010). Oscillation power in the $\gamma$-bandwidth $(30-80 \mathrm{~Hz})$ was computed in 10 -s time bins from spectrograms for each animal and averaged in 10-min bins.

\section{Morphology}

We filled cells with biocytin (0.1\%) during slice electrophysiology recordings and immediately fixed slices in $4 \%$ paraformaldehyde for $24-$ $48 \mathrm{~h}$ following recording (see Results for sample size used in each experiment). We washed slices three times for 10 min each with $1 \times$ PBS. We incubated slices overnight in streptavidin conjugated to Cy3 (Jackson ImmunoResearch; \#016-160-084). We washed slices three times for 
10 min each with $1 \times$ PBS and mounted the next day. To assess dendritic arbors, Z-stacks were reconstructed using Neurolucida software (MBF Bioscience). Sholl analysis was performed by counting basal and apical dendrite intersections across $10-\mu \mathrm{m}$ concentric circles.

RNA isolation and RT-qPCR

We collected S1 and ACC tissue punches from adolescent (PD40) mice which were stored at $-80^{\circ} \mathrm{C}$ until processing $(n=12-14$ mice per group). RNA was isolated and extracted from these samples using TRIzol (Invitrogen) and the MicroElute total RNA kit (Omega Bio-tek, Inc) with a DNase step. RNA concentrations were measured on a NanoDrop spectrophotometer, and 400-ng cDNA was then synthesized using an iScript cDNA synthesis kit (Bio-Rad Laboratories). mRNA expression changes were measured by RT-qPCR with Perfecta SYBR Green FastMix (Quanta) and quantified using a CFX384 system (BioRad Laboratories) using the $\Delta \Delta$ CT method as described previously (Fox et al., 2020) using GAPDH as a housekeeping gene. Primer sequences can be found in Table 2 .

\section{Results}

\section{Fentanyl exposure has no effect on dam health or maternal} care behavior

As we previously described (Alipio et al., 2020), we model perinatal fentanyl exposure by administering fentanyl citrate $(0,1$, 10 , or $100 \mu \mathrm{g} / \mathrm{ml}$ ) in the drinking water of pregnant mouse dams throughout their pregnancy and until their litters were weaned at PD21. Consistent with our previous study, in which we also administered $10 \mu \mathrm{g} / \mathrm{ml}$ fentanyl in the drinking water, we predicted that fentanyl administration would not influence the dam's general health ( $n=9-10$ dams per group; Fig. 1$)$. We compared body weight between different concentrations of fentanyl and vehicle control dams throughout pregnancy until weaning (Fig. 1B). There was no interaction between daily weight and fentanyl exposure groups [two-way repeated measures (RM) ANOVA, $\left.F_{(93,1023)}=0.88, p=0.76\right]$, nor a main effect of fentanyl exposure on dam weights (two-way RM ANOVA, $F_{(3,33)}=2.05$, $p=0.12$ ). We also assessed whether fentanyl exposure influences dams' liquid consumption (Fig. 1C). We found no interaction between daily liquid consumption and fentanyl exposure groups (two-way RM ANOVA, $F_{(93,1023)}=0.87, p=0.79$ ), nor did fentanyl exposure affect liquid consumption between groups across days (two-way RM ANOVA, $F_{(3,33)}=0.82, p=0.49$ ). We observed similar results with dams' food consumption (Fig. 1D). There was an interaction, with a medium effect size, between daily food consumption and fentanyl exposure (two-way RM ANOVA, $F_{(93,1023)}=1.49, p<0.002$, partial $\left.\eta^{2}=0.11\right)$; however, a post hoc multiple comparison analysis revealed no differences between exposure groups across each day (Tukey's post hoc test, $p>0.05)$. These data suggest that there is no difference in daily food consumption or effect of drug exposure between groups. Together, these data suggest that fentanyl exposure during pregnancy, at any of the concentrations tested, does not influence dams' total body weight, or liquid and food consumption.

Changes in maternal care during the early postnatal period can influence the development of neural systems, and their associated neurobiological and behavioral outputs (Meaney, 2001; Weaver et al., 2004). To assess maternal care behavior, we compared the time dams spent performing maternal care behaviors during 30-min sessions, twice a day, from PD1 to PD7 $(n=10$ dams per group; Fig. $1 E$ ). There was no interaction between fentanyl exposure and maternal care behaviors (two-way ANOVA, $\left.F_{(24,324)}=0.89, p=0.60\right)$, nor a main effect of fentanyl exposure (two-way ANOVA, $F_{(3,324)}=0.18, p=0.90$ ), which suggests that fentanyl exposure does not influence maternal care behavior.
Table 2. RT-qPCR Primer sequences

\begin{tabular}{|c|c|c|}
\hline Gene & Direction & Sequence \\
\hline \multirow[t]{2}{*}{ CB1R } & Forward & TGCGCTCTTGCACATGAACT \\
\hline & Reverse & CTGAACGCTGGCCTTACAGA \\
\hline \multirow[t]{2}{*}{$\mathrm{GABA}_{\mathrm{B} 1}$} & Forward & ACGTCACCTCGGAAGGTT \\
\hline & Reverse & CACAGGCAGGAAATTGATGGC \\
\hline \multirow{2}{*}{$\mathrm{GABA}_{\mathrm{B} 2}$} & Forward & AAG ACC CCA TAG AGG ACA TCA A \\
\hline & Reverse & GG TGG TAC GTG TCT GTG G \\
\hline \multirow[t]{2}{*}{$\mathrm{mGluR}_{1}$} & Forward & TGGAACAGAGCATTGAGTTCATC \\
\hline & Reverse & CAATAGGCTTCTTAGTCCTGCC \\
\hline \multirow[t]{2}{*}{$\mathrm{mGluR}_{2}$} & Forward & GCT CCC ACA GCT ATC ACC G \\
\hline & Reverse & TCA TAA CGG GAC TTG TCG CTC \\
\hline \multirow{2}{*}{$\mathrm{mGluR}_{3}$} & Forward & CTG GAG GCC ATG TTG TTT GC \\
\hline & Reverse & CAT CCA CTT TAG TCA ACG ATG CT \\
\hline \multirow[t]{2}{*}{$\mathrm{mGluR}_{4}$} & Forward & CCC ATA CCC ATT GTC AAG TTG G \\
\hline & Reverse & TGT AGC GCA CAA AAG TGA CCA \\
\hline \multirow[t]{2}{*}{$\mathrm{mGluR}_{5}$} & Forward & CACTGGGGTGCATTGTGTAG \\
\hline & Reverse & GGAGGAGTGCCTGTGTATCA \\
\hline \multirow[t]{2}{*}{$\mathrm{mGluR}_{7}$} & Forward & AGATGGTGGAATCTTTGGGGA \\
\hline & Reverse & ATTTACAGATGTGCATGGGGG \\
\hline \multirow[t]{2}{*}{$\mathrm{mGluR}_{8}$} & Forward & CGCTCGCGCAGTGATTATG \\
\hline & Reverse & CCC AAC TAT CTG AGC CAA TCC A \\
\hline \multirow[t]{2}{*}{ GluR $_{1}$} & Forward & TCC CCA ACA ATA TCC AGA TAG GG \\
\hline & Reverse & AAG CCG CAT GTT CCT GTG ATT \\
\hline \multirow[t]{2}{*}{ GluR $_{2}$} & Forward & TTC TCC TGT TTT ATG GGG ACT GA \\
\hline & Reverse & CTA CCC GAA ATG CAC TGT ATT CT \\
\hline \multirow[t]{2}{*}{$\mathrm{GluR}_{3}$} & Forward & ACC ATC AGC ATA GGT GGA CTT \\
\hline & Reverse & ACG TGG TAG TTC AAA TGG AAG G \\
\hline \multirow[t]{2}{*}{$\mathrm{GluR}_{4}$} & Forward & GTT TTC TGG ATT TTG GGG ACT CG \\
\hline & Reverse & AAG AGA CCA CCT ATT TGA ACG C \\
\hline \multirow[t]{2}{*}{ GluN2A } & Forward & ACG TGA CAG AAC GCG AAC TT \\
\hline & Reverse & TCA GTG CGG TTC ATC AAT AAC G \\
\hline \multirow[t]{2}{*}{ GluN2B } & Forward & AAAGAGTCGGGGGTGAACTT \\
\hline & Reverse & CGAGGGTTGCCTTCAGTAAG \\
\hline \multirow[t]{2}{*}{ GluN2C } & Forward & CATGGCCAGCTTATGACCTT \\
\hline & Reverse & CCAGGACAGGGACACATTTT \\
\hline \multirow[t]{2}{*}{ GluN2D } & Forward & GCT GCG AGA CTA TGG CTT CC \\
\hline & Reverse & CCA GTG ACG GGT TTA CCA GAA A \\
\hline \multirow[t]{2}{*}{ TRKB (full and short isoform) } & Forward & TTGTGTGGCAGAAAACCTTG \\
\hline & Reverse & ACAGTGAATGGAATGCACCA \\
\hline \multirow[t]{2}{*}{ BDNF (variants 1-12) } & Forward & GAAGAGCTGCTGGATGAGGAC \\
\hline & Reverse & TTCAGTTGGCCTTTTGATACC \\
\hline \multirow[t]{2}{*}{ GAPDH } & Forward & AGGTCGGTGTGAACGGATTTG \\
\hline & Reverse & TGTAGACCATGTAGTTGAGGTCA \\
\hline
\end{tabular}

To assess a more active form of maternal care, we performed a pup retrieval test on PD7 ( $n=9-11$ dams per group; Fig. $1 F-J)$. We compared latencies to sniff a pup, retrieve each of two pups, start nest building, and crouch over pups between fentanyl-exposed and control dams. We found no differences between groups in the latency to sniff a pup (ANOVA, $F_{(3,35)}=1.04, p=0.38$; Fig. $1 H$ ), retrieve the first pup (Kruskal-Wallis test, $H=3.26, p=0.35$; Fig. $1 G$ ), retrieve the second pup (ANOVA, $F_{(3,37)}=2.36, p=0.08$; Fig. $1 H$ ), nest build (ANOVA, $F_{(3,36)}=0.91, p=0.44$; Fig. $1 I$ ), or crouch over their pups (ANOVA, $F_{(3,37)}=1.43, p=0.24$; Fig. $1 J$ ). Taken together, these data suggest that fentanyl exposure during pregnancy does not adversely affect maternal care behaviors at any of the concentrations tested. We recognize, however, that we did not assess maternal care during the full postnatal period (PD8-PD21) and cannot exclude possible effects of maternal care during that period.

\section{Fentanyl exposure results in smaller litters and higher mortality}

Women who use opioids during pregnancy have increased incidence of sudden infant death syndrome and miscarriages 
A
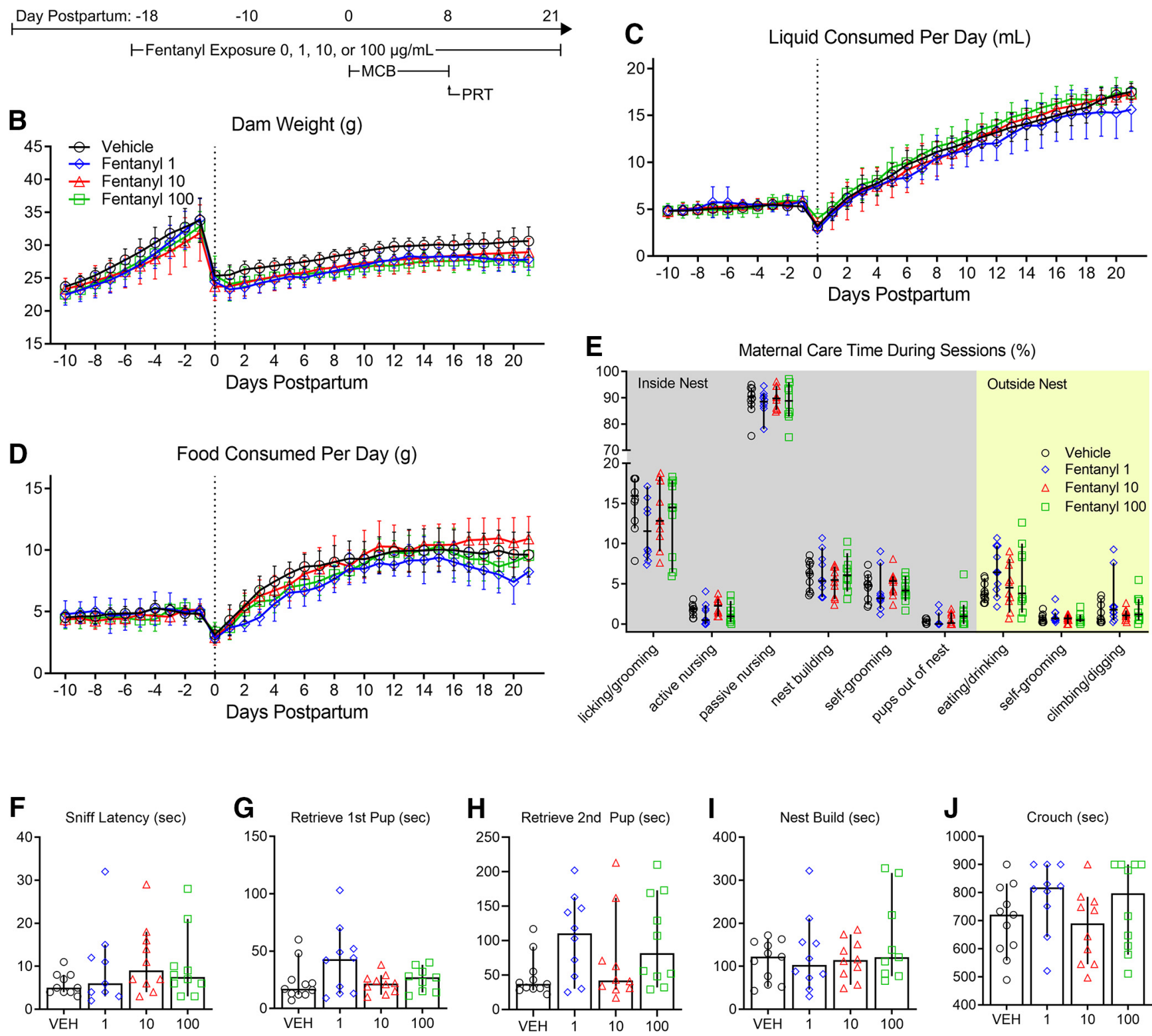

Figure 1. Perinatal fentanyl exposure does not influence dam health or maternal care. $\boldsymbol{A}$, Timeline depicting fentanyl exposure on dams, maternal care behavior, and pup retrieval test. There was no difference in dam weight $(\boldsymbol{B})$, liquid consumption $(\boldsymbol{C})$, or food consumption $(\boldsymbol{D})$ across all concentrations of fentanyl tested. $\boldsymbol{E}$, Fentanyl exposure did not adversely affect passive maternal care behaviors during PD1-PD7. $\boldsymbol{F}$-J, There were no differences between exposure groups in latencies to sniff, retrieve pups, start nest building, or crouch over pups. Data depict means for parametric or medians for non-parametric comparisons with $95 \%$ confidence intervals.

(Kandall et al., 1975; Kahila et al., 2010; Brogly et al., 2018). We predicted that this increased risk will be observed in litters perinatally exposed to opioids ( $n=12$ litters per group Fig. $2 B, C$ ). We compared the number of pups born from dams exposed to different concentrations of fentanyl or vehicle (Fig. 2B). There was a large effect of fentanyl exposure on the number of pups per litter (ANOVA, $F_{(3,44)}=14.89, p<10^{-4}$, partial $\eta^{2}=0.50$ ), with a large effect decrease in the number of pups per litter at birth that were exposed to each concentration of fentanyl tested, when compared with vehicle controls (Tukey's post hoc test, $1 \mu \mathrm{g} / \mathrm{ml}: p<10^{-4}$, Cohen's $d=2.51,10 \mu \mathrm{g} / \mathrm{ml}: p=0.001$, Cohen's $d=2.39,100 \mu \mathrm{g} / \mathrm{ml}: p<10^{-4}$, Cohen's $\left.d=2.30\right)$. There were no differences in the number of pups per litter between fentanyl exposure groups $(p>0.05)$. We assessed the litter mortality rate at weaning on PD21 (Fig. 2C). There was a large effect of fentanyl exposure on litter mortality rate (Kruskal-Wallis test, $H=13.92$, $p=0.003$, partial $\left.\eta^{2}=0.21\right)$. Post hoc analyses indicate a higher mortality rate with large effect sizes for litters that were exposed to each concentration of fentanyl tested, when compared with vehicle controls (Dunn's post hoc test, $1 \mu \mathrm{g} / \mathrm{ml}: p=0.01$, Glass' $\delta=3.79,10 \mu \mathrm{g} / \mathrm{ml}: p=0.01$, Glass' $\delta=2.92,100 \mu \mathrm{g} / \mathrm{ml}: p=0.01$, Glass' $\delta=3.11$ ). There were no differences in litter mortality rate between fentanyl exposure groups $(p>0.05)$. These data indicate that dams exposed to fentanyl during pregnancy, regardless of concentration, have smaller litters and a higher litter mortality rate compared with controls.

\section{Abnormal weight across early development}

Children prenatally exposed to opioids have lower weights and smaller head circumference compared with age matched controls 
A

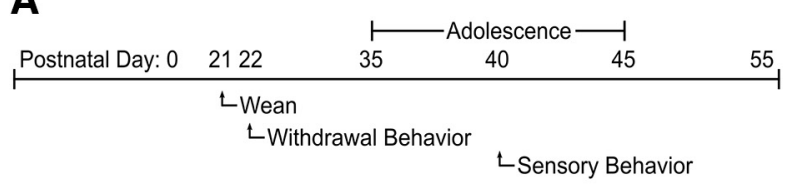

B Litter Size (\# pups/litter)
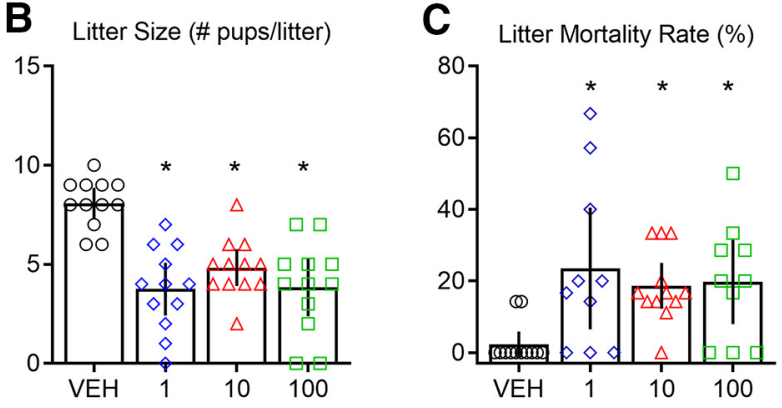

D

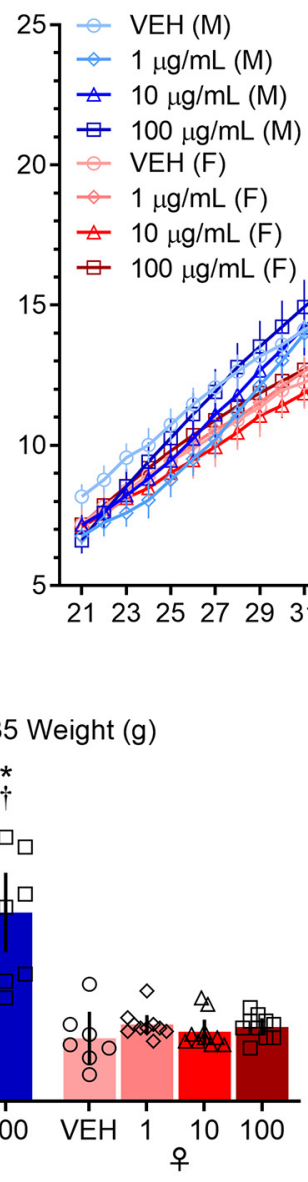

Pup Weight (g)

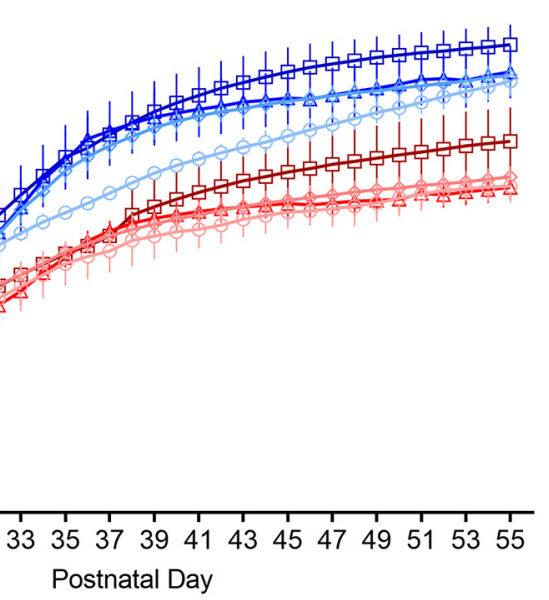

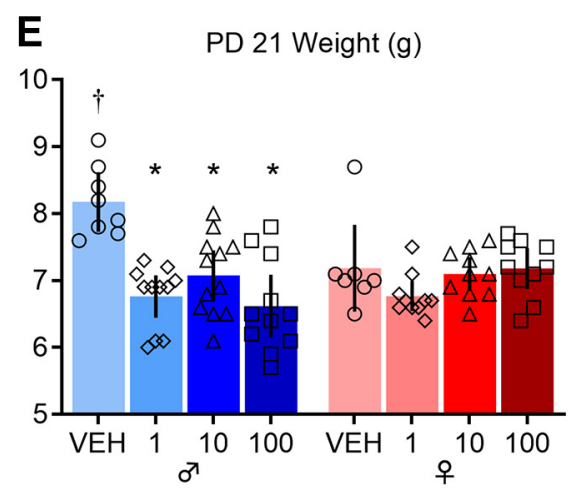

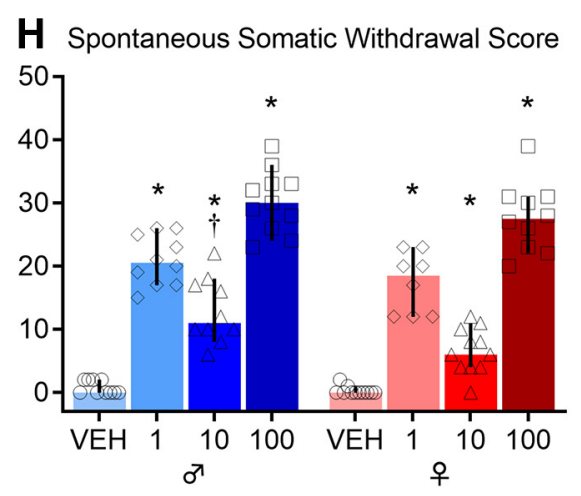

F

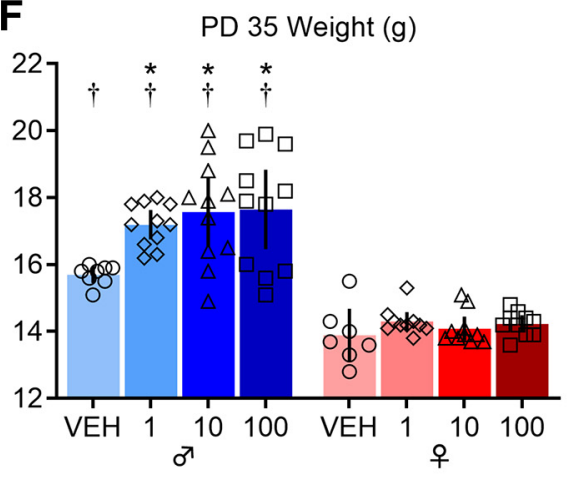

G

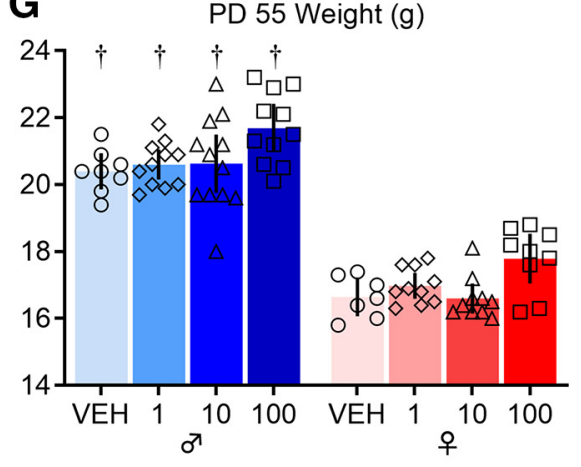

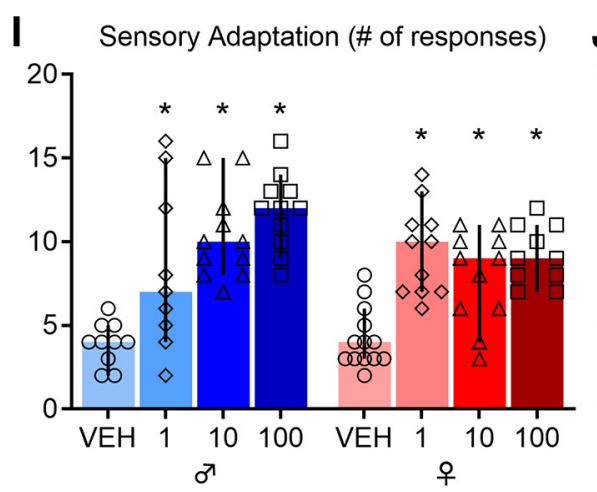

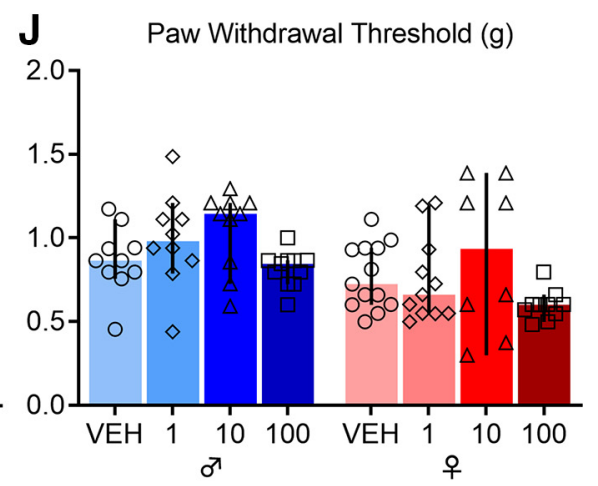

Figure 2. Perinatal fentanyl exposure results in aberrant effects at birth, withdrawal behavior, and impaired sensory function. $\boldsymbol{A}$, Timeline depicting withdrawal behavior $24 \mathrm{~h}$ after weaning and sensory behavior test during adolescence. Exposure resulted in smaller litter size $(\boldsymbol{B})$ and a higher litter mortality rate (C). D, Mice exposed to fentanyl perinatally exhibited abnormal weight during early development. $\boldsymbol{E}$, At weaning (PD21), exposed male mice weighed less than controls. $\boldsymbol{F}$, At adolescence (PD35), exposed male mice weighed more than controls and males weighed more than females at each concentration of fentanyl tested. $\boldsymbol{G}$, By adulthood (PD55), males weighed more than females, but there were no differences between fentanyl exposure groups. $\boldsymbol{H}$, Perinatal fentanyl exposure induces spontaneous somatic withdrawal behavior $24 \mathrm{~h}$ after cessation, at all concentrations of fentanyl tested. I, Perinatal fentanyl exposure impaired sensory adaptation to continuous application of tactile stimuli $(\boldsymbol{I})$ but did not influence paw withdrawal threshold $(\boldsymbol{J})$. Data depict means with $95 \%$ confidence intervals. $* p<0.05$ compared to vehicle control, $\uparrow p<0.05$ compared to opposite sex condition.

(Wilson et al., 1979; McPherson et al., 2015). We predicted that pups perinatally exposed to fentanyl would have abnormal body weight across development (PD21-PD55). To test this prediction, we measured body weight across development of pups perinatally exposed to different concentrations of fentanyl and compared them to controls $(n=8-11$ mice per group; Fig. $2 D-G)$. There was an interaction, with a large effect size, between perinatal fentanyl exposure and weight (two-way RM ANOVA, $F_{(238,2380)}=21.91, p<10^{-4}$, partial $\left.\eta^{2}=0.65\right)$, with a large main effect of fentanyl exposure (two-way RM ANOVA, $F_{(7,70)}=$ 30.41, $p<10^{-4}$, partial $\left.\eta^{2}=0.83\right)$. These data suggest perinatal fentanyl exposure influences body weight across development.

To assess body weight at specific developmental periods, we tested whether pups perinatally exposed to fentanyl had abnormal body weight at weaning (PD21; Fig. 2E). There was an interaction, with a large effect size, between perinatal fentanyl exposure and sex (two-way ANOVA, $F_{(3,71)}=6.45, p=0.001$, partial $\eta^{2}=0.23$ ). Exposed males, but not females, weighed less 
than vehicle controls, with a large effect size (Tukey's post hoc test, $1 \mu \mathrm{g} / \mathrm{ml}: p<10^{-4}$, Cohen's $d=2.82,10 \mu \mathrm{g} / \mathrm{ml}: p=0.004$, Cohen's $d=1.96,100 \mu \mathrm{g} / \mathrm{ml}: p<10^{-4}$, Cohen's $\left.d=2.51\right)$. There were no differences in weight between fentanyl exposure groups $(p>0.05)$ and, as expected, vehicle males weighed more than vehicle females (Tukey's post hoc test, $p=0.01$, Cohen's $d=1.59$ ).

At adolescence (PD35; Fig. 2F) there was no interaction between perinatal fentanyl exposure and sex (two-way ANOVA, $\left.F_{(3,70)}=2.49, p=0.06\right)$. There were main effects of drug exposure (two-way ANOVA, $F_{(3,70)}=4.55, p=0.005$, partial $\eta^{2}=0.16$ ), and sex (two-way ANOVA, $F_{(1,70)}=161.2, p<10^{-4}$, partial $\eta^{2}=$ $0.64)$. Exposed males, but not females, weighed more than vehicle controls, with a large effect size (Tukey's post hoc test, $1 \mu \mathrm{g} /$ $\mathrm{ml}: p=0.03$, Cohen's $d=2.96,10 \mu \mathrm{g} / \mathrm{ml}: p=0.003$, Cohen's $d=1.65,100 \mu \mathrm{g} / \mathrm{ml}: p=0.001$, Cohen's $d=1.54$ ). There were no differences in weight between fentanyl exposure groups $(p>0.05)$. Males weighed more than females at all concentrations tested (Tukey's post hoc test, VEH: $p=0.01$, Cohen's $d=2.82,1 \mu \mathrm{g} / \mathrm{ml}: p<10^{-4}$, Cohen's $d=5.39,10 \mu \mathrm{g} / \mathrm{ml}: p<10^{-4}$, Cohen's $d=2.99,100 \mu \mathrm{g} / \mathrm{ml}: p<10^{-4}$, Cohen's $\left.d=2.69\right)$.

By adulthood (PD55; Fig. 2G) there was no interaction between perinatal fentanyl exposure and sex (two-way ANOVA, $\left.F_{(3,70)}=0.20, p=0.89\right)$. There were large main effects of drug exposure (two-way ANOVA, $F_{(3,70)}=7.64, p=0.0002$, partial $\eta^{2}=$ 0.22 ), and sex (two-way ANOVA, $F_{(1,70)}=351.9, p<10^{-4}$, partial $\left.\eta^{2}=0.77\right)$. In male and female groups, there were no differences in weight when comparing across all fentanyl concentrations tested (Tukey's post hoc test, $p>0.05$ ). Males weighed more than females at all concentrations tested (Tukey's post hoc test, VEH: $p<10^{-4}$, Cohen's $d=5.94,1 \mu \mathrm{g} / \mathrm{ml}: p<10^{-4}$, Cohen's $d=6.00$, $10 \mu \mathrm{g} / \mathrm{ml}: p<10^{-4}$, Cohen's $d=3.78,100 \mu \mathrm{g} / \mathrm{ml}: p<10^{-4}$, Cohen's $d=3.83$ ).

Taken together, these results indicate that perinatal fentanyl exposure only affects the body weight of males at weaning. At all other age groups examined, neither males nor females that were treated perinatally differed in weight from age or sex-matched controls.

\section{Fentanyl withdrawal behavior}

Newborns exposed to opioids in utero may develop NOWS. Twenty-four hours after weaning (PD21), at a time when fentanyl was expected to have cleared in treated mice (Hug and Murphy, 1981), we tested whether perinatally exposed mice exhibited spontaneous somatic withdrawal signs $(n=8-11$ mice per group; Fig. $2 H)$. There was no interaction between sex and exposure (two-way ANOVA, $F_{(3,73)}=1.81, p=0.15$ ). There were large main effects of sex (two-way ANOVA, $F_{(1,73)}=12.69$, $p=0.0007$, partial $\eta^{2}=0.14$ ) and fentanyl exposure (two-way ANOVA, $F_{(3,73)}=189.5, p<10^{-4}$, partial $\left.\eta^{2}=0.88\right)$. Exposed males had higher withdrawal scores compared with controls, with a large effect size, at all concentrations tested (Tukey's post hoc test, $1 \mu \mathrm{g} / \mathrm{ml}: p<10^{-4}$, Cohen's $d=6.90,10 \mu \mathrm{g} / \mathrm{ml}: p<10^{-4}$, Cohen's $d=3.29,100 \mu \mathrm{g} / \mathrm{ml}: p<10^{-4}$, Cohen's $\left.d=8.25\right)$. Males exposed to $100 \mu \mathrm{g} / \mathrm{ml}$ had higher withdrawal scores compared with males exposed to $1 \mu \mathrm{g} / \mathrm{ml}$ (Tukey's post hoc test, $p<10^{-4}$, Cohen's $d=2.08$ ) or $10 \mu \mathrm{g} / \mathrm{ml}$ (Tukey's post hoc test, $p<10^{-4}$, Cohen's $d=3.46$ ). Males exposed to $1 \mu \mathrm{g} / \mathrm{ml}$ had higher withdrawal scores compared with males exposed to $10 \mu \mathrm{g} / \mathrm{ml}$ (Tukey's post hoc test, $p=0.0009$, Cohen's $d=1.75$ ).

Exposed females also had higher withdrawal scores compared with controls, with a large effect size (Tukey's post hoc test, $1 \mu \mathrm{g} /$ $\mathrm{ml}: p<10^{-4}$, Cohen's $d=4.95,10 \mu \mathrm{g} / \mathrm{ml}: p=0.009$, Cohen's $d=2.47,100 \mu \mathrm{g} / \mathrm{ml} p<10^{-4}$, Cohen's $d=7.00$ ). Females exposed to $100 \mu \mathrm{g} / \mathrm{ml}$ had higher withdrawal scores compared with females exposed to $1 \mu \mathrm{g} / \mathrm{ml}$ (Tukey's post hoc test, $p<10^{-4}$, Cohen's $d=1.99$ ) or $10 \mu \mathrm{g} / \mathrm{ml}$ (Tukey's post hoc test, $p<10^{-4}$, Cohen's $d=4.53$ ). Males exposed to $10 \mu \mathrm{g} / \mathrm{ml}$ had higher withdrawal scores compared with females exposed to $10 \mu \mathrm{g} / \mathrm{ml}$ (Tukey's post hoc test, $p=0.01$, Cohen's $d=1.42$ ). The expression of withdrawal signs supports the conclusion that our model recapitulates opioid exposure during pregnancy in humans.

\section{Impaired sensory adaptation in adolescent mice}

Adolescent children prenatally exposed to opioids may exhibit lasting somatosensory deficits (Kivisto et al., 2015) that may be independent of the expression of NOWS (Bakhireva et al., 2019). Adaptation, the cessation of a paw withdrawal response, to repeated stimuli is a key measure of sensory processing. We predicted that adolescent mice perinatally exposed to different concentrations of fentanyl would have impaired adaptation to repeated tactile stimuli ( $n=10-12$ mice per group; Fig. $2 I$ ). We compared the number of paw withdrawal responses to repeated application of a punctate stimulus that evoked withdrawal responses at threshold forces (see Materials and Methods). Compared with control mice, fentanyl-exposed mice failed to adapt, that is, they continued to respond to the stimuli. There was an interaction, with a medium effect size, between sex and fentanyl exposure (two-way ANOVA, $F_{(3,78)}=2.736, p=0.04$, partial $\left.\eta^{2}=0.09\right)$. Fentanyl-exposed males had a higher number of paw withdrawal responses compared with controls, with a large effect size at all concentrations tested (Tukey's post hoc test, $1 \mu \mathrm{g} / \mathrm{ml}: p=0.01$, Cohen's $d=1.23,10 \mu \mathrm{g} / \mathrm{ml}$ : $p<10^{-4}$, Cohen's $d=3.06,100 \mu \mathrm{g} / \mathrm{ml}: p<10^{-4}$, Cohen's $d=4.28$ ). Likewise, exposed females had a higher number of paw withdrawal responses compared with controls, with a large effect size at all concentrations tested (Tukey's post hoc test, $1 \mu \mathrm{g} / \mathrm{ml}: p=0.0002$, Cohen's $d=2.30,10 \mu \mathrm{g} / \mathrm{ml}: p=0.02$, Cohen's $d=1.57,100 \mu \mathrm{g} / \mathrm{ml}$ : $p=0.0007$, Cohen's $d=2.80$ ).

The failure to adapt was not because of reduced sensitivity to stimuli, because the responses to punctate stimuli elicited similar responses in both groups. We used von Frey filaments to test paw withdrawal thresholds ( $n=10-12$ mice per group; Fig. $2 J$ ). There was no interaction between sex and fentanyl exposure (two-way ANOVA, $F_{(3,75)}=0.38, p=0.76$ ). There was a medium main effect of sex (two-way ANOVA, $F_{(1,75)}=11.39, p=0.001$, partial $\eta^{2}=0.13$ ) and a large effect of fentanyl exposure (twoway ANOVA, $F_{(1,75)}=4.15, p=0.008$, partial $\eta^{2}=0.14$ ). However, there were no differences in paw withdrawal thresholds within sex or exposure groups compared with controls (Tukey's post hoc test, $p>0.05$ ). Taken together, these findings suggest that perinatal fentanyl exposure impairs adaptation to repeated tactile stimulation but does not influence mice's ability to sense tactile stimuli.

\section{Decreased excitatory synaptic transmission in S1}

Behavioral deficits in tactile sensory perception and processing are associated with changes in synaptic transmission in S1 (Fox et al., 2000). Therefore, we predicted that adolescent mice perinatally exposed to different concentrations of fentanyl would have impaired excitatory synaptic transmission in S1 (Fig. 3). We recorded miniature EPSCs (mEPSCs) in S1 layer 5 neurons from adolescent mice, in the presence of gabazine, a $\mathrm{GABA}_{\mathrm{A}}$ receptor antagonist ( $N=4-5$ mice per group, $n=2-5$ neurons per mouse). Figure $3 B$ depicts mEPSCs recorded from adolescent male and female mice perinatally exposed to different concentrations of fentanyl or vehicle control. We assessed the inter-event intervals, the reciprocal of their frequency, from 3-min recordings 


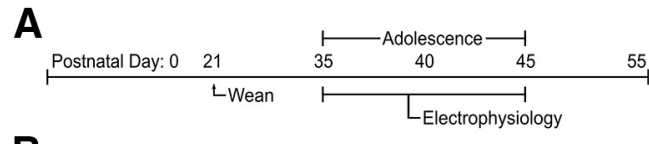

B

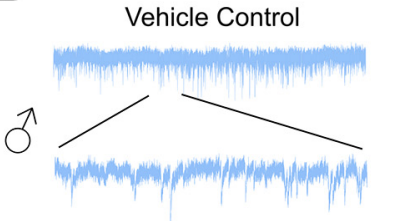

Fentanyl $1 \mu \mathrm{g} / \mathrm{mL}$
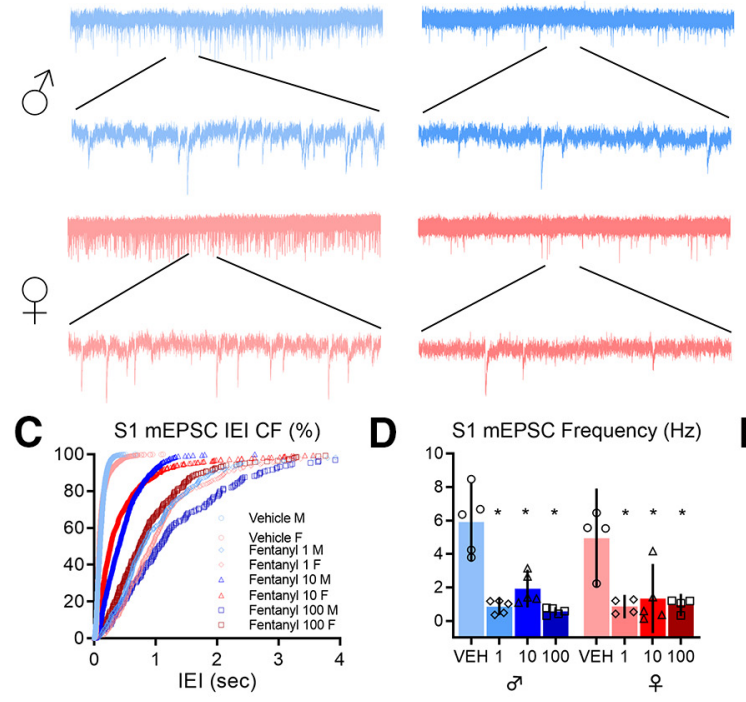

G
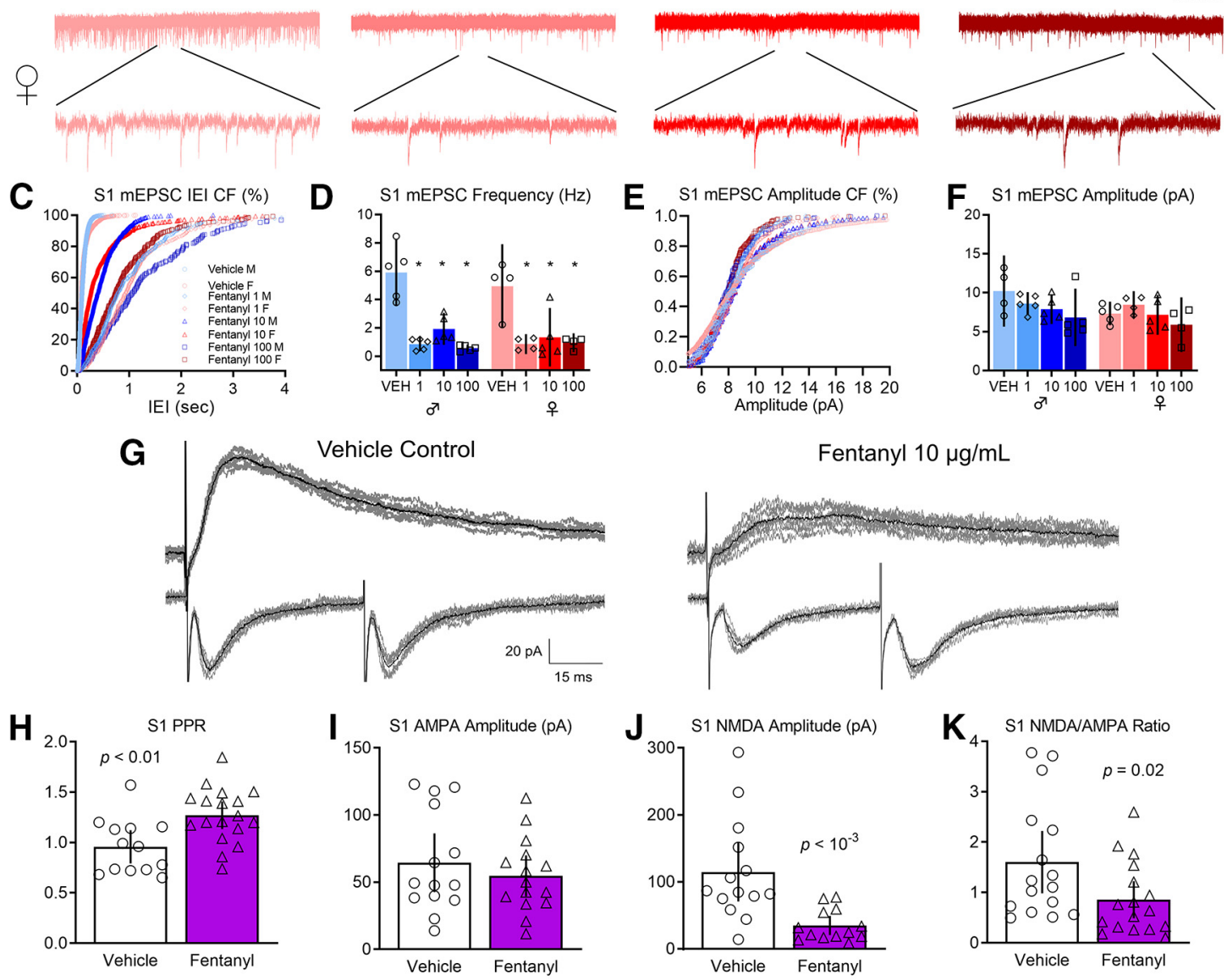

Fentanyl $10 \mu \mathrm{g} / \mathrm{mL}$

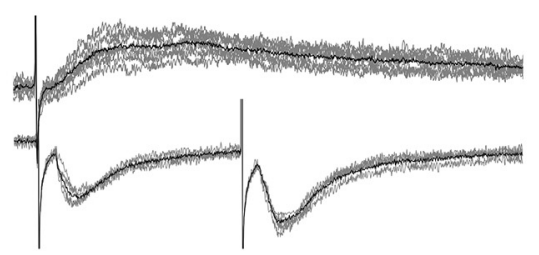

L

mIPSCs
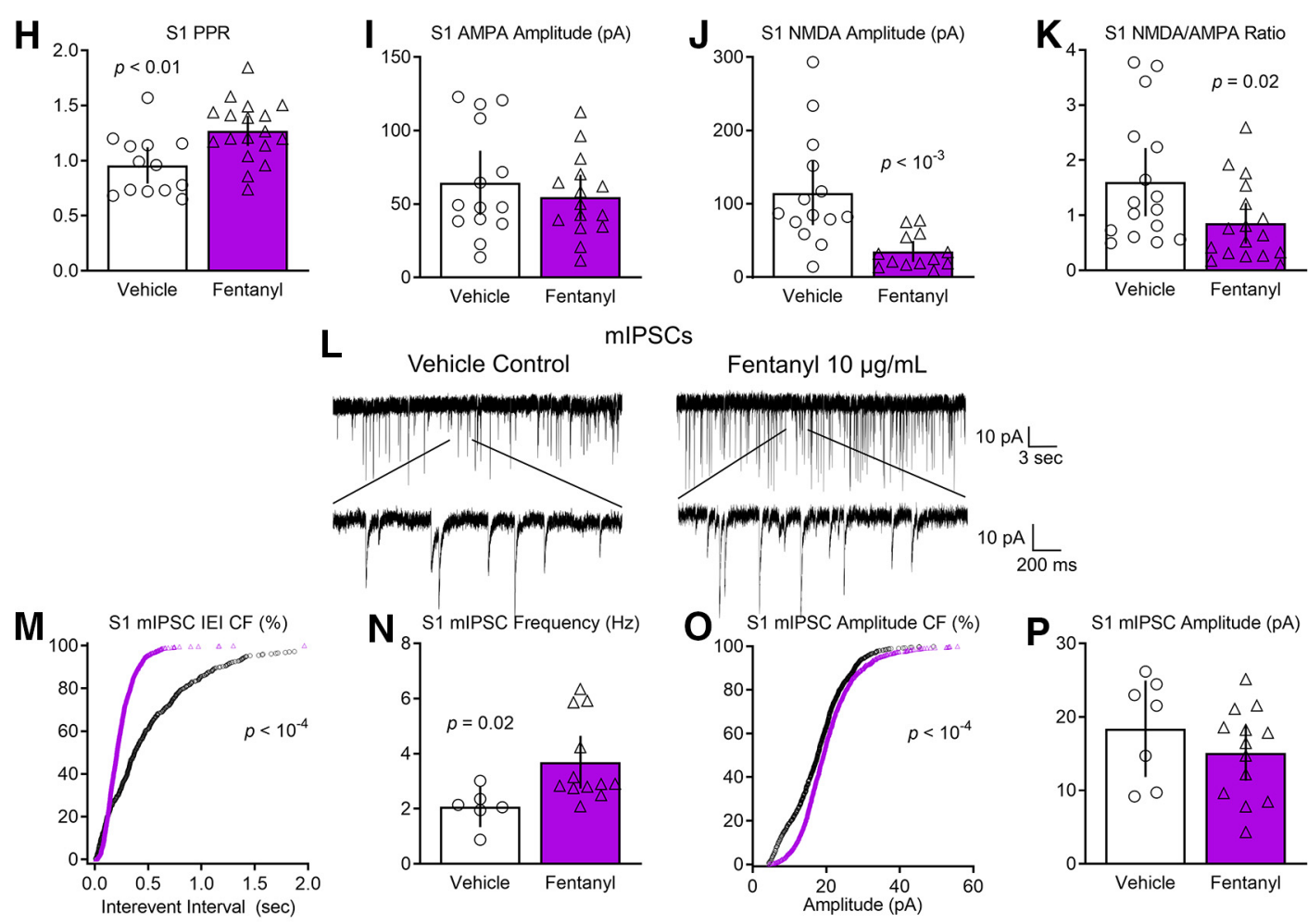

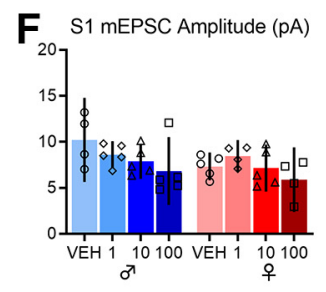

Fentanyl $100 \mu \mathrm{g} / \mathrm{mL}$

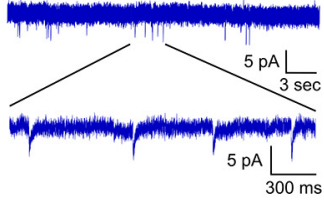

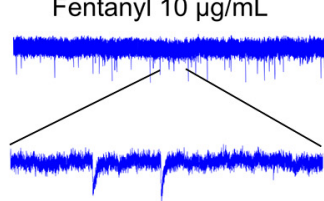
(1)

mEPSCs 
(Fig. 3C). There was a rightward shift in the cumulative frequency plot of the inter-event interval in fentanyl-exposed mice compared with controls (Kruskal-Wallis test, $H=3244, p<10^{-4}$, partial $\eta^{2}=$ 0.50 ). The cumulative frequency was shifted to the right in fentanylexposed male mice compared with controls, with a large effect size at all concentrations tested (Dunn's post hoc test, $1 \mu \mathrm{g} / \mathrm{ml}: p<10^{-4}$, Hedges' $g=4.72,10 \mu \mathrm{g} / \mathrm{ml}: p<10^{-4}$, Hedges' $g=2.23,100 \mu \mathrm{g} / \mathrm{ml}$ : $p<10^{-4}$, Hedges' $g=5.16$ ). Similarly, there was a rightward shift in the cumulative frequency of the inter-event intervals in fentanyl exposed females compared with controls, with a large effect size (Dunn's post hoc test, $1 \mu \mathrm{g} / \mathrm{ml}: p<10^{-4}$, Hedges' $g=4.51,10 \mu \mathrm{g} / \mathrm{ml}$ : $p<10^{-4}$, Hedges' $g=1.09,100 \mu \mathrm{g} / \mathrm{ml}: p<10^{-4}$, Hedges' $g=3.52$ ).

The frequency of mEPSCs in these samples were lower in fentanyl-exposed mice, compared with controls. We averaged data from all neurons recorded from each animal and considered each animal as a single sample (Fig. 3D). This analysis revealed that mEPSCs in fentanyl-exposed mice were 3-fold less frequent than those in controls. There was no interaction between sex and fentanyl exposure (two-way ANOVA, $F_{(3,29)}=0.57, p=0.63$ ). There was a main effect of fentanyl exposure with a large effect size (two-way ANOVA, $F_{(3,29)}=30.58, p<10^{-4}$, partial $\eta^{2}=$ 0.75 ) and no effect of sex (two-way ANOVA, $F_{(1,29)}=0.54$, $p=0.46$ ). Fentanyl-exposed males had a lower frequency of mEPSCs compared with controls, with a large effect size at all concentrations tested (Tukey's post hoc test, $1 \mu \mathrm{g} / \mathrm{ml}: p<10^{-4}$, Cohen's $d=3.66,10 \mu \mathrm{g} / \mathrm{ml}: p=0.0003$, Cohen's $d=2.66,100 \mu \mathrm{g} /$ $\mathrm{ml}: p<10^{-4}$, Cohen's $\left.d=3.93\right)$. Similarly, fentanyl exposed females also had a lower frequency of mEPSCs compared with controls, with a large effect size at all concentrations tested (Tukey's post hoc test, $1 \mu \mathrm{g} / \mathrm{ml}: p=0.0009$, Cohen's $d=3.02$, $10 \mu \mathrm{g} / \mathrm{ml}: p=0.002$, Cohen's $d=2.04,100 \mu \mathrm{g} / \mathrm{ml}: p=0.001$, Cohen's $d=2.96$ ). There were no differences in the frequency of mEPSCs between male or female exposure groups regardless of fentanyl concentration (Tukey's post hoc test, $p>0.05$ ) These data indicate that perinatal fentanyl exposure results in lower frequency of mEPSCs in S1 neurons of adolescent mice.

There were shifts in the cumulative frequency of mEPSC amplitudes between fentanyl-exposed mice compared with controls, with a small effect size (Kruskal-Wallis test, $H=543.9$, $p<10^{-4}$, partial $\eta^{2}=0.21$; Fig. $3 E$ ). The cumulative frequency of the amplitude was shifted to the left in fentanyl-exposed male mice compared with controls at all concentrations tested (Dunn's post hoc test, $1 \mu \mathrm{g} / \mathrm{ml}: p<10^{-4}$, Hedges' $g=0.35,10 \mu \mathrm{g} / \mathrm{ml}$ : $p<10^{-4}$, Hedges' $g=0.29,100 \mu \mathrm{g} / \mathrm{ml}: p<10^{-4}$, Hedges' $\left.g=0.57\right)$. In female mice, there were no differences between vehicle control and the $1 \mu \mathrm{g} / \mathrm{ml}$ fentanyl group (Dunn's post hoc test, $p=0.17$ ), a rightward shift in the $10 \mu \mathrm{g} / \mathrm{ml}$ fentanyl group, with a small effect size $\left(p<10^{-4}\right.$, Hedges' $\left.g=0.24\right)$, and a leftward shift in the $100 \mu \mathrm{g} / \mathrm{ml}$ fentanyl group, with a small effect size $(p=0.0008$, Hedges' $g=0.21$ ).

When data from all cells from a single animal are averaged, and comparisons are made between treated and control animals, we find no differences in amplitudes of mEPSCs in S1 neurons

\footnotetext{
$(\boldsymbol{H})$. There were no differences in AMPAR-mediated response amplitude $(\boldsymbol{I})$. $\boldsymbol{J}$, There was decreased NMDAR-mediated response amplitude, which is also reflected in the NMDA/AMPA ratio $(\boldsymbol{K})$. $\boldsymbol{L}$, Example traces of mIPSCs. $\boldsymbol{M}$, Cumulative frequency plot of the interevent intervals of mIPSCs are shifted to the left in fentanyl-exposed mice compared with controls. $\mathbf{N}$, Grouped data reflect increased mIPSC frequency in fentanyl-exposed mice. $\mathbf{0}$, Cumulative frequency plot of the mIPSC amplitude was shifted to the right. $\boldsymbol{P}$, There were no differences in grouped data of mIPSC amplitude. Data depict means for parametric or medians for nonparametric comparisons with 95\% confidence intervals.
}

between sex or exposure groups (Fig. $3 F$ ). There was no interaction between sex and fentanyl exposure (two-way ANOVA, $\left.F_{(3,29)}=0.78, p=0.51\right)$. There was no main effect of fentanyl exposure (two-way ANOVA, $F_{(1,29)}=2.70, p=0.06$ ) nor a main effect of sex (two-way ANOVA, $F_{(1,29)}=3.21, p=0.08$ ).

These data suggest that perinatal fentanyl exposure does not impact postsynaptic current responses in adolescent mice.

Since there were no significant interactions between sex and fentanyl exposure, nor a main effect of sex in any of the mEPSC analyses, we grouped and analyzed male and female mice according to exposure conditions. We performed subsequent experiments in mice exposed to $10 \mu \mathrm{g} / \mathrm{ml}$ fentanyl, since there were no robust concentration-dependent difference in the dependent variables tested above. Additionally, this concentration of fentanyl elicits affective and sensory deficits, and is the optimal concentration that mice will readily self-administer (Wade et al., 2008; Alipio et al., 2020).

\section{Evoked responses}

To determine whether fentanyl exposure affects evoked responses, we recorded electrically evoked EPSCs from S1 layer 5 neurons in ACSF containing gabazine to block inhibitory activity. Stimulating electrodes were placed below the recording neuron in layer 6 . Figure $3 G$ depicts paired pulse responses recorded from mice perinatally exposed to fentanyl or vehicle control. The paired pulse ratio is calculated by dividing the amplitude of the second pulse by the amplitude of the first pulse. Note that the ratio is higher in the mouse perinatally exposed to fentanyl, compared with the control. Group analysis revealed that perinatal fentanyl exposure led to an increased paired pulse ratio of evoked EPSCs recorded from S1 neurons, which was of a large effect size $(N=13-18$ mice per group, $n=2-5$ neurons per mouse, unpaired $t$ test, $t_{(29)}=3.14$, $p=0.003$, Cohen's $d=1.14$; Fig. $3 H$ ). Because changes in paired pulse ratios primarily reflect changes in presynaptic mechanisms (Zucker and Regehr, 2002), these findings suggest that perinatal fentanyl exposure results in reductions in presynaptic glutamate release in adolescent mice.

\section{NMDA/AMPA receptor ratios}

Figure $3 G$ depicts examples of evoked responses in which the AMPAR and NMDAR components of the response were isolated, as described in Materials and Methods. Note the smaller NMDA amplitude in fentanyl-exposed mouse, compared with the control. Group analysis revealed a reduction in the NMDAR/ AMPAR ratio, with a medium effect size $(N=13-17$ mice per group, $n=2-5$ neurons per mouse, unpaired $t$ test, $t_{(31)}=2.23$, $p=0.03$, Cohen's $d=0.77$; Fig. $3 K$ ). This is reflected by a large effect decrease in the NMDAR-mediated EPSC amplitude (Mann-Whitney test, $U=19, p=0.0002$, Glass' $\delta=1.04$; Fig. $3 J)$, and no difference in AMPAR-mediated EPSC amplitude (unpaired $t$ test, $t_{(27)}=0.79, p=0.43$; Fig. $3 I$ ).

Together, these data indicate that perinatal fentanyl exposure impairs spontaneous and evoked excitatory synaptic transmission in S1 neurons in adolescent mice. And that this impairment is mediated both by a reduction in presynaptic glutamate release and a reduction in postsynaptic, NMDAR-mediated responses.

\section{Increased inhibitory synaptic transmission in S1}

Cortical activity involves both excitatory and inhibitory synaptic transmission. To determine whether perinatal fentanyl exposure influences inhibitory synaptic transmission in S1, we compared miniature IPSCs (mIPSCs) in S1 layer 5 neurons from adolescent mice perinatally exposed to fentanyl or vehicle control $(N=7-10$ 
mice per group, $n=2-5$ neurons per mouse). Figure $3 L$ depicts mIPSCs recorded from a mouse perinatally exposed to fentanyl or a vehicle control. The frequency of mIPSCs in these samples is higher in the fentanyl-exposed mouse. The cumulative probability of the interevent interval was shifted to the left in fentanylexposed mice compared with controls, with a small effect size (Kolmogorov-Smirnov test, $D=0.26, p<10^{-4}$, Hedges' $g=0.20$; Fig. $3 M$ ). As a group, fentanyl-exposed mice exhibited a large effect increase in mIPSC frequency (unpaired $t$ test, $t_{(16)}=2.48$, $p=0.02$, Cohen's $d=1.38$; Fig. $3 N$ ). These data suggest that perinatal fentanyl exposure increases the frequency of inhibitory spontaneous vesicle release events in S1 neurons from adolescent mice.

There was a rightward shift in the cumulative frequency of mIPSC amplitudes in fentanyl-exposed mice, which is of a small effect size (Kolmogorov-Smirnov test, $D=0.21, p<10^{-4}$, Hedges' $g=0.29$; Fig. 3O). This difference is driven by a larger number of events at lower amplitudes. However, when data from all cells from a single animal are averaged, and comparisons are made between treated and control animals, we find no difference in mIPSC amplitude (unpaired $t$ test, $t_{(18)}=1.08$, $p=0.29$; Fig. $3 P$ ).

These data suggest that perinatal fentanyl exposure increases spontaneous inhibitory synaptic transmission in S1 neurons from adolescent mice, and that these changes may be expressed through a presynaptic mechanism.

\section{Increased excitatory synaptic transmission in ACC}

The ACC has been implicated in complex sensory processing behaviors (Kennerley et al., 2006) and behavioral adaptation to environmental stimuli (Brockett et al., 2020). Since perinatal fentanyl exposure impaired sensory adaptation in adolescent mice, we predicted that synaptic transmission in ACC from exposed mice would also be impaired (Fig. 4). Surprisingly, the changes in the adolescent ACC of perinatally treated mice were opposite to those we identified in S1.

We recorded mEPSCs in ACC layer 5 neurons from adolescent mice perinatally exposed to fentanyl or vehicle control ( $N=8-10$ mice per group, $n=2-5$ neurons per mouse). Figure $4 B$ includes sample recordings depicting increased frequency and amplitude of mEPSCs recorded in ACC layer 5 neurons from an exposed mouse or a vehicle control. The cumulative frequency plot of the interevent intervals was shifted to the left in fentanyl-exposed mice compared with controls, with a large effect size (Kolmogorov-Smirnov test, $D=0.58, p<10^{-4}$, Hedges' $g=1.79$; Fig. $4 C$ ). As a group, fentanyl-exposed mice exhibited a large effect increase of mEPSC frequency in ACC neurons (unpaired $t$ test, $t_{(18)}=3.43, p=0.003$, Cohen's $d=1.53$; Fig. 4D).

The cumulative frequency of the amplitude was shifted to the right in fentanyl-exposed mice, with a medium effect size (Kolmogorov-Smirnov test, $D=0.38, p<10^{-4}$, Hedges' $g=0.59$; Fig. $4 E$ ). However, as a group, there was no difference in the average mEPSC amplitude (unpaired $t$ test, $t_{(17)}=0.75, p=0.46$; Fig. $4 F$ ). As discussed above, this discrepancy might reflect a specific effect on a subset of mEPSCs.

These data suggest that perinatal fentanyl exposure increases the frequency of spontaneous excitatory synaptic transmission in ACC neurons from adolescent mice.

\section{Evoked responses}

Similar to S1, we investigated whether perinatal fentanyl exposure impairs evoked excitatory synaptic transmission in ACC layer 5 neurons. Stimulating electrodes were placed below the recording neuron in layer 6 . Figure $4 G$ depicts the paired pulse responses recorded from the ACC of a mouse perinatally exposed to fentanyl or control. Note the decreased paired pulse ratio in the fentanyl-exposed mouse. Group analysis revealed that fentanyl-exposed mice exhibit a large effect decrease in the paired pulse ratio of AMPAR-mediated EPSCs recorded from ACC neurons $(N=9-10$ mice per group, $n=2-5$ neurons per mouse, unpaired $t$ test, $t_{(18)}=5.73, p<10^{-4}$, Cohen's $d=2.56$; Fig. 4H).

\section{NMDA/AMPA receptor ratios}

Figure $4 G$ depicts example traces of evoked AMPAR and NMDAR-mediated currents. There was no difference in the AMPAR-mediated EPSC amplitude $(N=8-11$ mice per group, $n=2-5$ neurons per mouse, unpaired $t$ test, $t_{(19)}=0.32$, $p=0.74$; Fig. 4I), the NMDAR-mediated EPSC amplitude (Mann-Whitney test, $U=16, p=0.05$; Fig. $4 J$ ), or in the NMDAR/AMPAR ratio (Mann-Whitney test, $U=37, p=0.14$; Fig. $4 K)$. These data suggest that perinatal fentanyl exposure increases evoked excitatory transmission to ACC neurons, likely through presynaptic mechanisms.

\section{No changes in inhibitory synaptic transmission in ACC}

Figure $4 L$ depicts mIPSCs recorded from an adolescent mouse perinatally exposed to fentanyl and a control. There was a leftward shift in the cumulative frequency of the interevent interval of fentanyl-exposed mice compared with controls, with a large effect size $(N=14-18$ mice per group, $n=2-5$ neurons per mouse, Kolmogorov-Smirnov test, $D=0.43, p<10^{-4}$, Hedges' $g=1.16$; Fig. $4 M$ ). There was no difference in the average mIPSC frequency between groups (unpaired $t$ test, $t_{(30)}=0.68, p=0.49$; Fig. 4N).

Likewise, the cumulative frequency of the amplitude was shifted to the left in fentanyl-exposed mice compared with controls, with a small effect size $(N=7-12$ mice per group, $n=2-5$ neurons per mouse, Kolmogorov-Smirnov test, $D=0.08$, $p<10^{-4}$, Hedges' $g=0.08$; Fig. 4O). There was no difference in average mIPSC amplitude between groups (unpaired $t$ test, $t_{(17)}=0.21, p=0.83$; Fig. $4 P$ ). These data suggest that perinatal fentanyl exposure does not influence spontaneous inhibitory synaptic transmission to ACC neurons of adolescent mice.

Taken together, these findings suggest that, in adolescent mice, the largest effects of perinatal fentanyl exposure is decreased presynaptic release of glutamate in S1, and an increase of this release in ACC.

\section{Reduced cortical oscillatory response}

The changes in synaptic efficacies described above suggest that network activity in mice perinatally exposed to fentanyl may be affected. Using electrocorticography (ECoG), we assessed synchronous network activity from large neuronal populations. We and others have previously shown that reproducible ECoG oscillations, particularly in the $\gamma(30$ to $80 \mathrm{~Hz})$ range, can be evoked by injecting a subanesthetic dose of ketamine $(10 \mathrm{mg} / \mathrm{kg})$, an NMDAR antagonist (Raver et al., 2013; Raver and Keller, 2014). We used this approach to compare $\gamma$ power change in fentanyl exposed and control mice ( $n=7-9$ mice per group; Fig. 5). Figure $5 B$ depicts ECoGs recorded from adolescent mice treated perinatally with either fentanyl or vehicle, along with the spectrograms (Fig. $5 C, D$ ) of these recordings. Note that the increase in $\gamma$-band activity in the treated mouse is smaller than that in the control. Group analysis revealed no interaction between sex and 
A

B

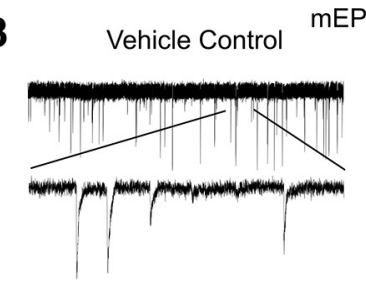

C acc mepsciei cf (\%)

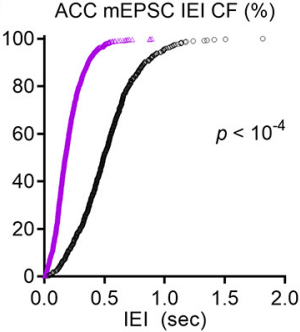

D ACC mEPSC Frequency $(\mathrm{Hz})$

E ACC mEPSC Amplitude CF (\%)
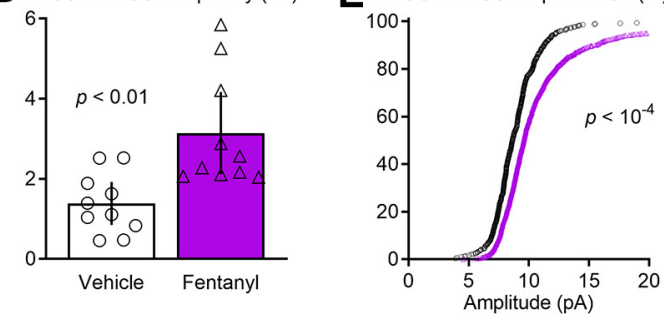

Fentanyl $10 \mu \mathrm{g} / \mathrm{mL}$

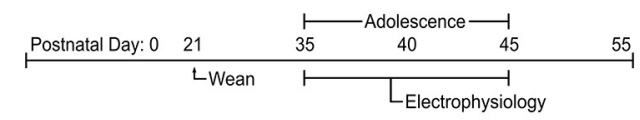

G

Vehicle Control

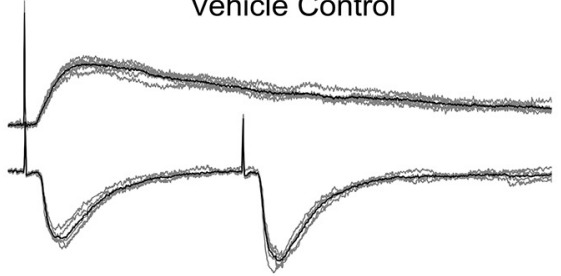

Fentanyl $10 \mu \mathrm{g} / \mathrm{mL}$
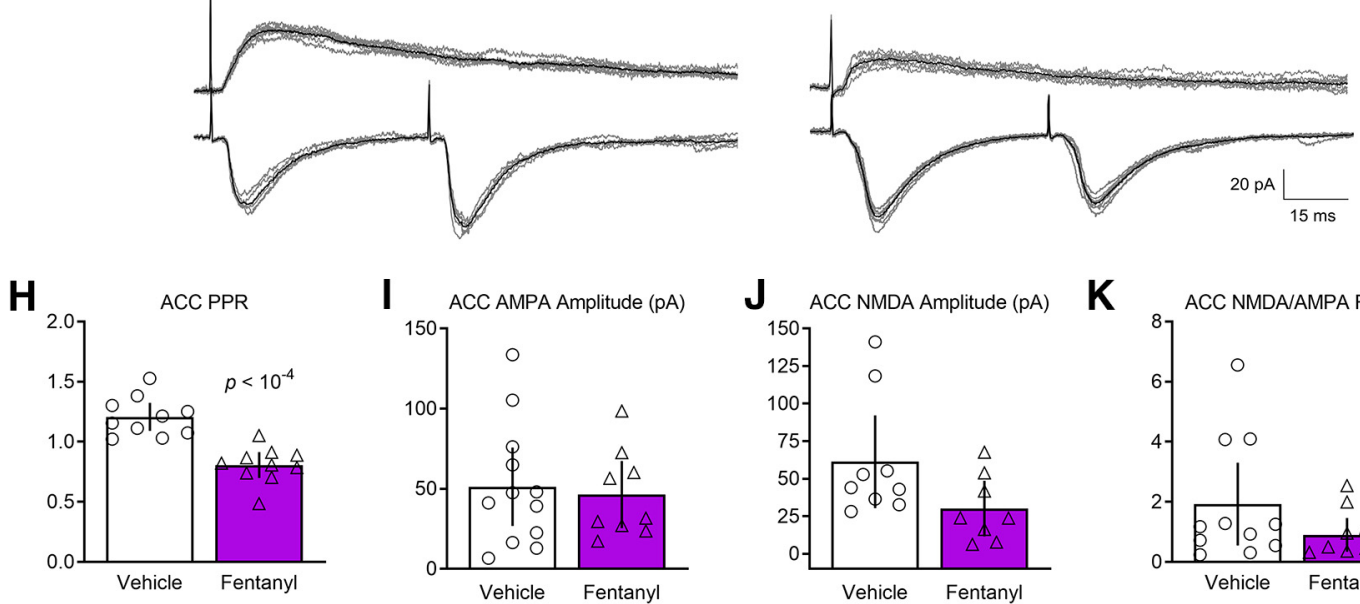

I ACC AMPA Amplitude (pA)

J

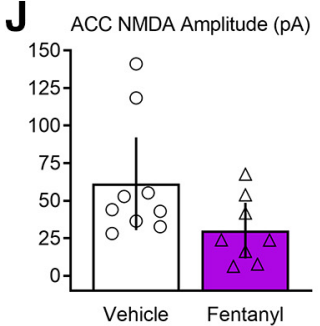

K

- ACC mEPSC Amplitude (pA)
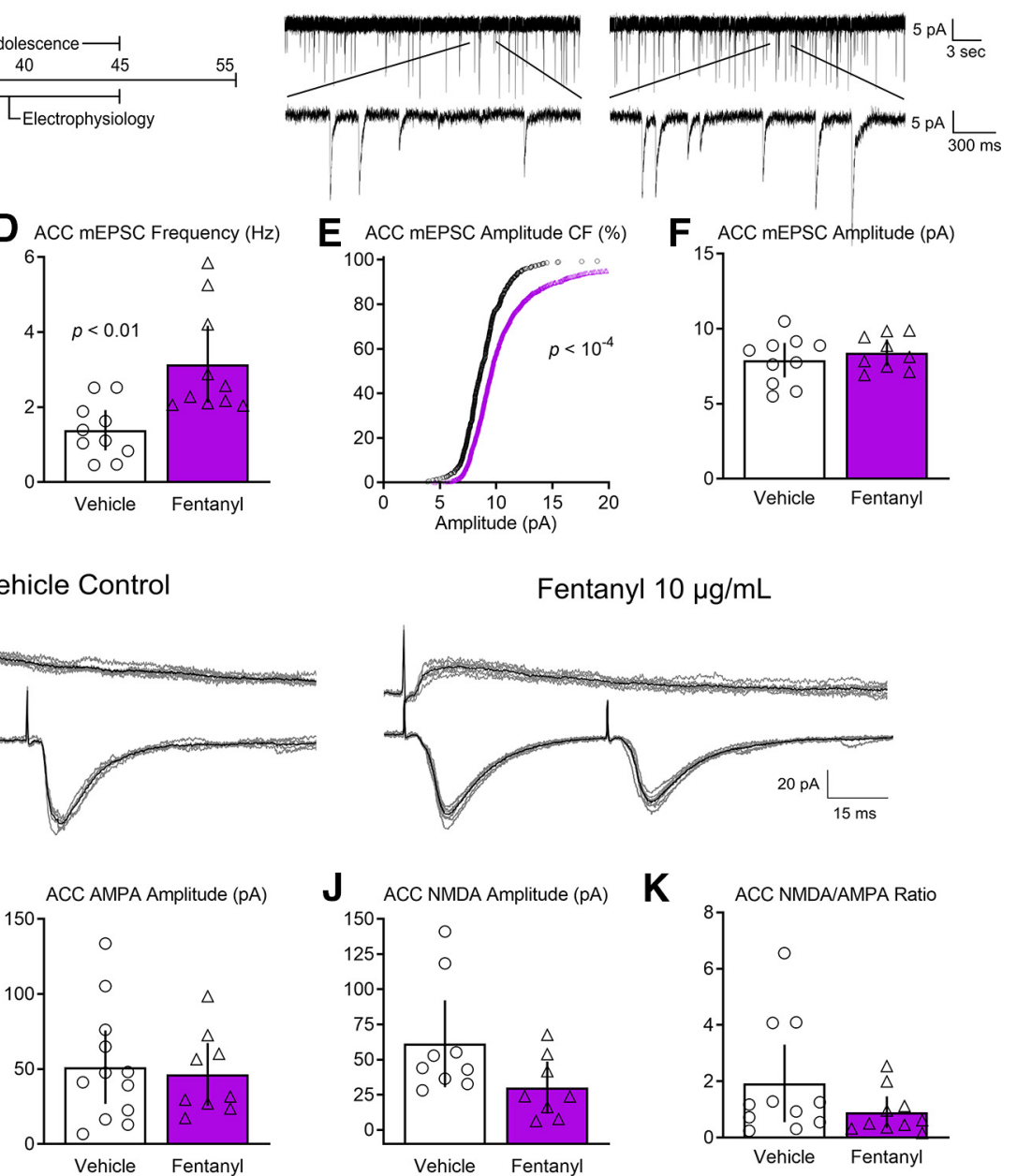

$\mathbf{L}$

mIPSCs
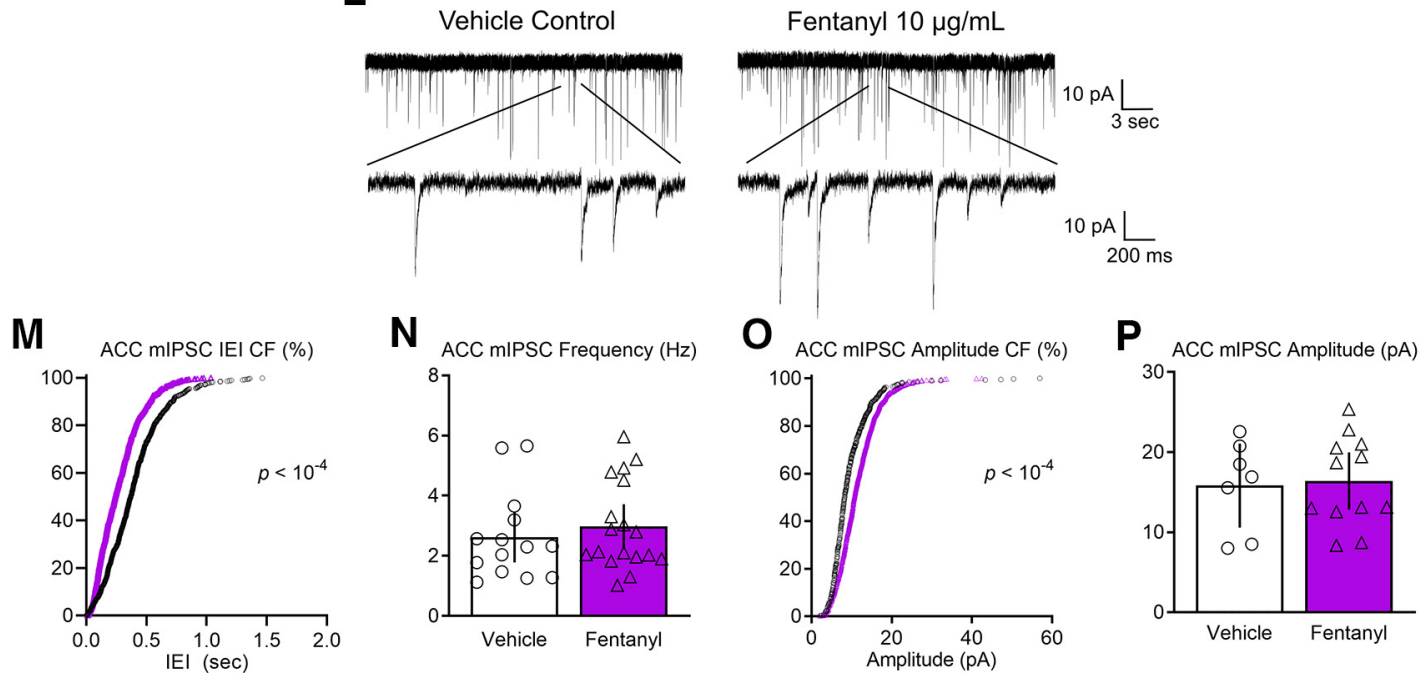

Figure 4. Perinatal fentanyl exposure impairs synaptic transmission in anterior cingulate cortical neurons. $A$, Timeline depicting slice electrophysiology recordings in ACC layer 5 neurons of adolescent mice. $\boldsymbol{B}$, Example traces of mEPSCs. C, Cumulative frequency plot of the interevent intervals of mEPSCs are shifted to the left in fentanyl-exposed mice compared with controls. $\boldsymbol{D}$, Grouped data reflect increased $\mathrm{mEPSC}$ frequency in fentanyl-exposed mice. $\boldsymbol{E}$, Cumulative frequency of the mEPSC amplitude was shifted to the right in fentanyl-exposed mice. $\boldsymbol{F}$, There were no differences in grouped data of mEPSC amplitudes. $\boldsymbol{G}$, Example traces of evoked paired pulse and NMDAR-mediated responses. $\boldsymbol{H}$, Perinatal fentanyl exposure results in decreased paired pulse ratio in fentanyl-exposed mice. There were no differences in AMPAR-mediated response amplitudes ( $\boldsymbol{l})$, NMDAR-mediated response amplitudes $(\boldsymbol{I})$, or the NMDA/AMPA ratio $(\boldsymbol{K})$. $\boldsymbol{L}$, Example traces of mIPSCS. $\boldsymbol{M}$, Cumulative frequency plot of the interevent intervals of mIPSCs are shifted to the left in fentanyl-exposed mice compared with controls. $\boldsymbol{N}$, There were no differences in grouped data of mIPSC frequency. $\mathbf{0}$, Cumulative frequency plot of the mIPSC amplitude was shifted to the right. $\boldsymbol{P}$, There were no differences in grouped data of mIPSC amplitude. Data depict means for parametric or medians for non-parametric comparisons with $95 \%$ confidence intervals. 
A

\begin{tabular}{lllll} 
& & & Adolescence $\longrightarrow$ & -1 \\
Postnatal Day: 0 & 21 & 30 & 40 & 45 \\
\hline ᄂWean & ᄂECoG Implant & ᄂBehavior
\end{tabular}

B

Vehicle

Fentanyl

Baseline
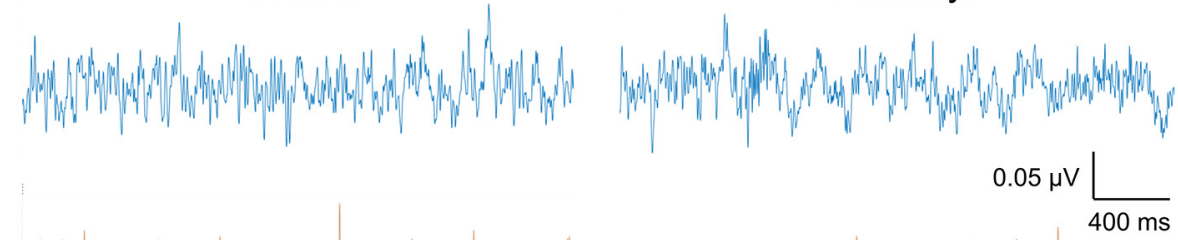

Post Ketamine

C
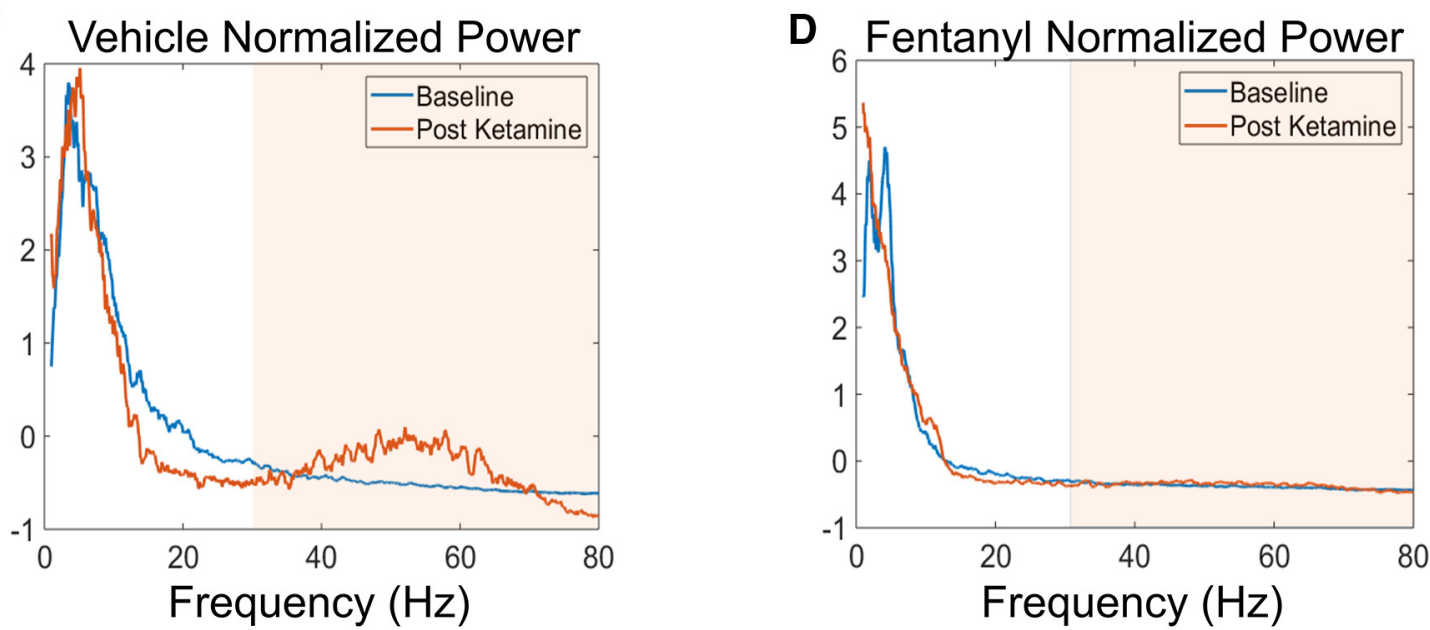

E Gamma Power (\% $\Delta$ from Baseline)

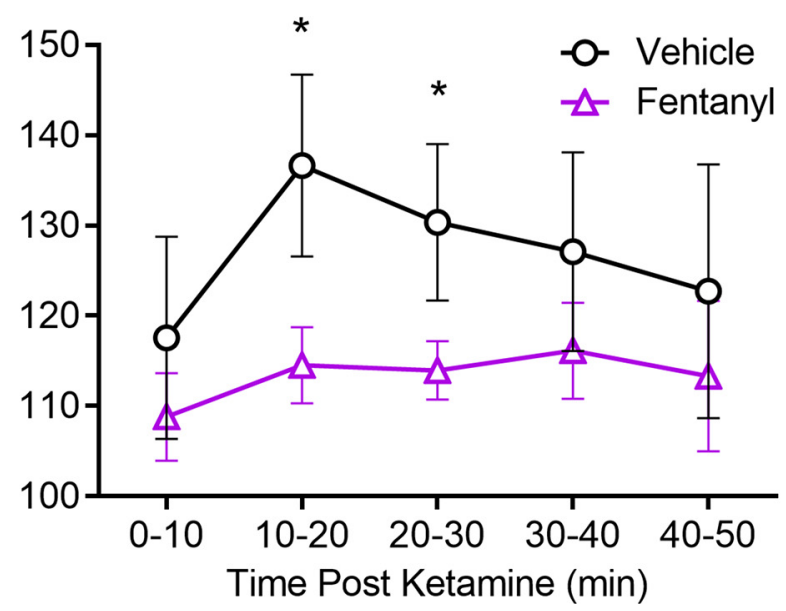

Figure 5. Perinatal fentanyl exposure reduces ketamine-evoked cortical oscillations. $\boldsymbol{A}$, Timeline depicting transmitter implant and in vivo ECoG recordings. $\boldsymbol{B}$, Example ECoG traces of cortical oscillations recorded from fentanyl or vehicle control adolescent mice, before and after intraperitoneal injection of subanesthetic dose of ketamine (10 $\mu \mathrm{g} / \mathrm{ml})$. Normalized power of cortical oscillations in control $(\boldsymbol{C})$ and perinatal fentanyl exposed $(\boldsymbol{D})$ adolescent mice. $\boldsymbol{E}$, Grouped data of $\gamma$ power across 10-min time bins after ketamine injection. Data depict means with $95 \%$ confidence intervals. $* p<0.05$. 
exposure across all time points (two-way RM ANOVA, $F_{(4,56)}=$ $1.41, p=0.24$; Fig. $5 E$ ), therefore, mice were grouped according to fentanyl exposure. There was a large main effect of fentanyl exposure $\left(F_{(1,14)}=36.74, p<10^{-4}\right.$, partial $\left.\eta^{2}=0.41\right)$. Exposed mice exhibited smaller $\gamma$-band activity at both the $10-20 \mathrm{~min}$ (Bonferroni's post hoc test, $p=0.005)$ and $20-30 \mathrm{~min}(p=0.01)$ postketamine time points. These data suggest that perinatal fentanyl exposure reduces ketamine-evoked $\gamma$-band cortical activity in awake adolescent mice.

\section{Reduced branching of pyramidal neurons}

Perinatal morphine exposure can delay dendritic development in cortical pyramidal neurons (Ricalde and Hammer, 1990). To determine whether perinatal fentanyl exposure influences dendritic morphology we analyzed the morphologies of layer 5 neurons in S1 and ACC (Fig. 6). Note the reduced dendritic complexity in pyramidal neurons from fentanyl-exposed mice (Fig. 6B).

S1 basal dendrites from fentanyl-exposed mice had less complex branching, evidenced as a smaller number of Sholl intersections ( $n=5-7$ mice per group; Fig. $6 C$ ). There was a large effect interaction between fentanyl exposure and the number of intersections across dendritic branch distance from the soma (twoway RM ANOVA, $F_{(23,207)}=3.21, p<10^{-4}$, partial $\left.\eta^{2}=0.26\right)$, with a smaller number of intersections between $70-120 \mu \mathrm{m}$ distance from the soma (Bonferroni's post hoc test; $p<0.05$ ). Sholl analyses of S1 apical dendrites also revealed a main effect of fentanyl exposure (two-way RM ANOVA, $F_{(1,9)}=5.99, p=0.03$, partial $\eta^{2}=0.13$; Fig. $6 D$ ), and smaller number of intersections (two-way RM ANOVA, $F_{(3,28)}=10.89, p<10^{-4}$, partial $\eta^{2}=$ $0.54)$.

Fentanyl exposure was associated with a large effect reduction in somata diameter (unpaired $t$ test, $t_{(10)}=2.95, p=0.01$, Cohen's $d=1.75$; Fig. $6 G$ ), as well as a reduction in total dendritic length (unpaired $t$ test, $t_{(10)}=3.40, p=0.006$, Cohen's $d=2.03$; Fig. $6 H$ ) of $\mathrm{S} 1$ pyramidal neurons.

As in S1, ACC basal dendrites from fentanyl-exposed mice had smaller number of Sholl intersections, with a small effect size $\left(n=12-19\right.$ mice per group; two-way RM ANOVA, $F_{(31,899)}=$ $1.50, p=0.03$, partial $\eta^{2}=0.04$; Fig. $6 E$ ). There was no difference in the number of intersections of ACC apical dendrites (Fig. $6 F$ ). There was no interaction between fentanyl exposure and the number of intersections across dendritic branch distance from the soma (two-way RM ANOVA, $F_{(41,1189)}=0.64, p=0.96$ ), nor a main effect of drug exposure (two-way RM ANOVA, $F_{(1,29)}=$ $0.17, p=0.67)$.

There were no differences in somata diameter (unpaired $t$ test, $t_{(28)}=0.41, p=0.68$; Fig. $6 I$ ), nor in total dendritic length (unpaired $t$ test, $t_{(28)}=0.94, p=0.35$; Fig. $6 J$ ) in ACC pyramidal neurons.

Together, these data suggest perinatal fentanyl exposure decreases the dendritic arbor, length, and soma diameter of S1 pyramidal neurons. The dendritic arbor of basal dendrites in ACC were similarly decreased.

\section{Decreased mRNA expression of tropomyosin receptor kinase $B(\operatorname{TrkB})$ in S1}

Brain-derived neurotrophic factor (BDNF) and its receptor, TrkB, are involved in growth, development, and maturation of neurons in S1 (Lush et al., 2005). Therefore, the changes in dendritic morphology in pyramidal neurons suggest a corresponding change in the expression of BDNF and TrkB in S1 of adolescent mice ( $n=13-14$ mice per group). Indeed, there was a large effect decrease in the expression of $\operatorname{TrkB}$ in $\mathrm{S} 1$ (unpaired $t$ test, $t_{(25)}=$ $2.48, p=0.01$, Cohen's $d=0.95$; Fig. $6 K$ ). There was no difference in the expression of BDNF (Mann-Whitney test, $U=69$, $p=0.30$; Fig. $6 L$ ). There were no differences in expression of TrkB (unpaired $t$ test, $t_{(25)}=1.74, p=0.09$; Fig. $6 M$ ) or BDNF in the ACC (unpaired $t$ test, $t_{(24)}=0.48, p=0.63$; Fig. $6 N$ ). RTqPCR primers for BDNF target transcript variants $1-12$ and primers for TrkB target full-length and short-length isoforms.

These results indicate that decreased mRNA expression of TrkB in S1 corroborates with decreased dendritic arbor, length, and soma size of S1 layer 5 pyramidal neurons. As predicted, there were no differences in expression of BDNF or TrkB in the ACC since there were small effect differences in the morphologic analysis of the dendritic arbor.

\section{Increased cannabinoid receptor 1 (CB1R) mRNA expression in S1, decreased in ACC}

CB1R is a $G_{i / o}$ coupled heteroreceptor and are presynaptically expressed on both inhibitory and excitatory neurons in S1 and ACC (Lomazzo et al., 2017; Yeh et al., 2017). Activation of $\mathrm{CB} 1 \mathrm{Rs}$ suppresses presynaptic release. We tested whether perinatal fentanyl exposure affects mRNA expression of CB1Rs in S1 and ACC of adolescent mice. In S1, there was a large effect increased expression of CB1Rs (unpaired $t$ test, $t_{(25)}=2.41$, $p=0.02$, Cohen's $d=0.92$; Table 1 ), whereas in ACC there was a large effect decreased expression (unpaired $t$ test, $t_{(25)}=2.75$, $p=0.01$, Cohen's $d=1.05$ ). These findings demonstrate that changes in CB1R expression parallel the changes in presynaptic release occurring after perinatal fentanyl exposure, suggesting that these changes may be causally related.

\section{Increased $\mathrm{GABA}_{\mathrm{B}}$ receptor $\mathrm{mRNA}$ expression in ACC}

A third mechanism of presynaptic transmitter regulation in neocortex involves $\mathrm{GABA}_{\mathrm{B}}$ receptors. In $\mathrm{ACC}$, where there was an increase in mEPSC frequency, there was a large effect decrease mRNA expression of $\mathrm{GABA}_{\mathrm{B} 1}$ (unpaired $t$ test, $t_{(24)}=2.54$, $p=0.01$, Cohen's $d=0.99$; Table 1$)$. There was no difference in expression of $\mathrm{GABA}_{\mathrm{B} 2}$ receptors (unpaired $t$ test, $t_{(25)}=0.28$, $p=0.77)$. In $S 1$, where there was a decrease in mEPSC frequency, there was no difference in expression of $\mathrm{GABA}_{\mathrm{B} 1}$ (unpaired $t$ test, $t_{(25)}=0.27, p=0.78$ ), nor in $\mathrm{GABA}_{\mathrm{B} 2}$ (Mann-Whitney test, $U=64, p=0.46)$. Thus, in ACC, but not in S1, changes in $\mathrm{GABA}_{\mathrm{B}}$ receptor mRNA expression were correlated with the electrophysiological findings.

\section{Metabotropic glutamate receptor (mGluR) mRNA expression}

In addition to $\mathrm{CB} 1 \mathrm{R}, \mathrm{mGluRs}$ regulate synaptic transmission. We compared the mRNA expression of several mGluR subtypes in adolescent mice perinatally exposed to fentanyl, with controls. In $\mathrm{S} 1$, there was a large effect decrease in expression of $\mathrm{mGluR}_{8}$ (Mann-Whitney test, $U=42, p=0.01$, Glass' $\delta=0.78$; Table 1 ). There was no difference in expression of the other group-3 mGluRs: $\mathrm{mGluR}_{4}$ (unpaired $t$ test, $t_{(25)}=0.53, p=0.59$ ) or $\mathrm{mGluR}_{7}$ (unpaired $t$ test, $t_{(25)}=0.31, p=0.75$ ). There were no differences in group- 1 mGluRs: mGluR $_{1}$ (unpaired $t$ test, $t_{(24)}=$ $0.46, p=0.13$ ) and $\mathrm{mGluR}_{5}$ (unpaired $t$ test, $t_{(25)}=0.14, p=0.88$ ), nor in group-2 mGluRs: mGluR $_{2}$ (unpaired $t$ test, $t_{(25)}=0.13$, $p=0.89$ ) and $\mathrm{mGluR}_{3}$ (unpaired $t$ test, $t_{(25)}=0.77, p=0.44$ ). Group-3 mGluR $_{8}$ receptors inhibit transmitter release and are expressed on both glutamatergic and GABAergic terminals (Shigemoto et al., 1997; Ferraguti et al., 2005). Given the 3-fold decrease of S1 excitatory transmission, the decreased expression 
A

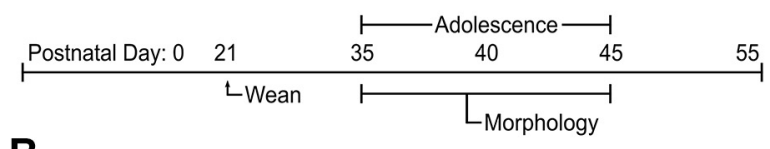

B

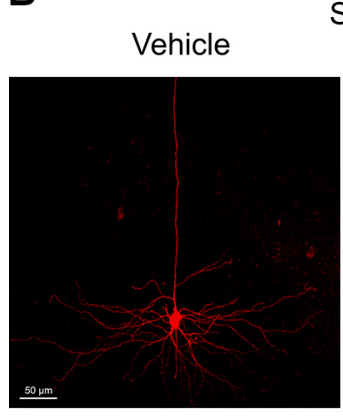

S1

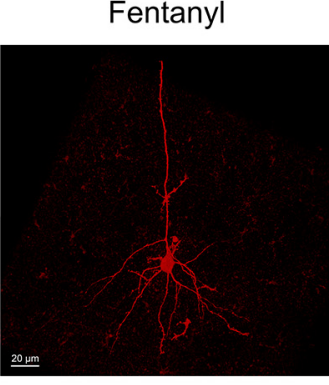

C S1 Basal Dendrites (\# of intersections)
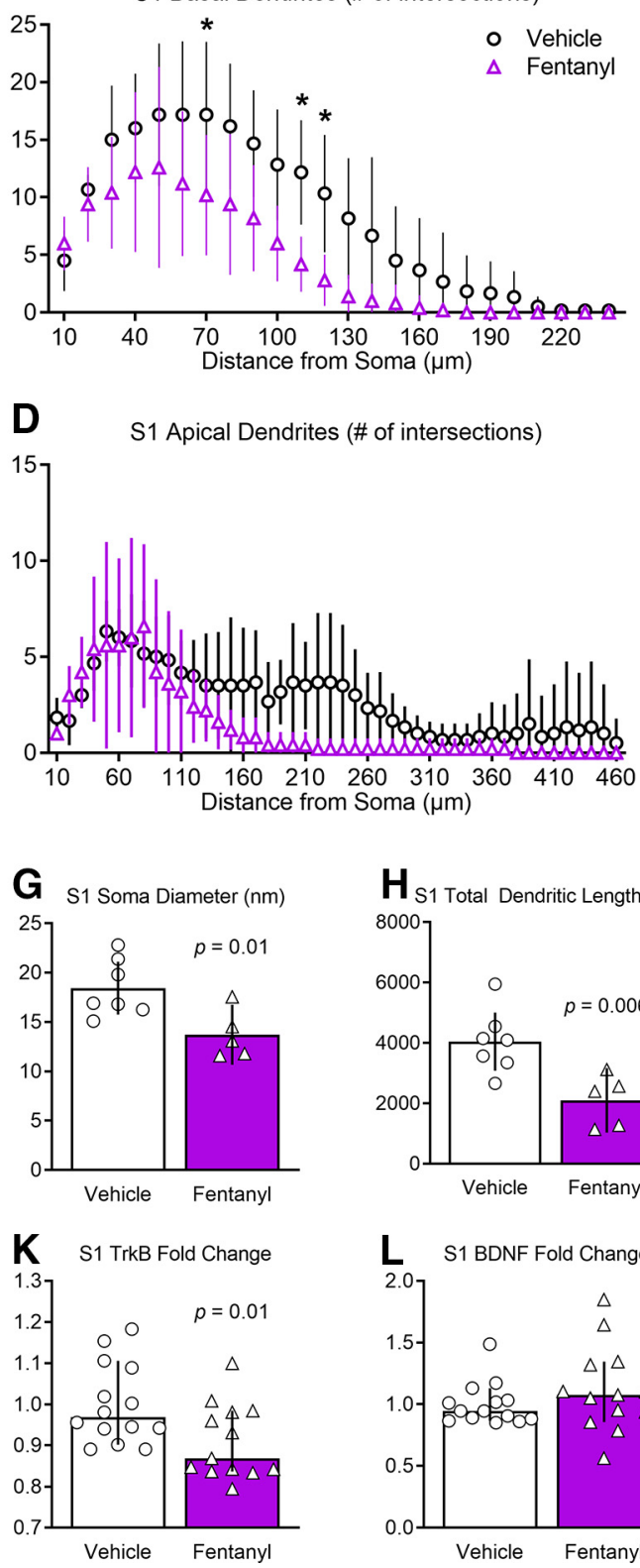
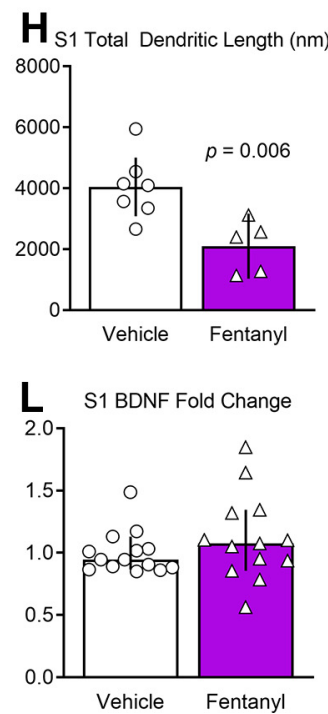

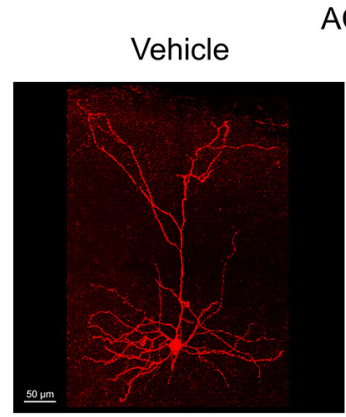

ACC
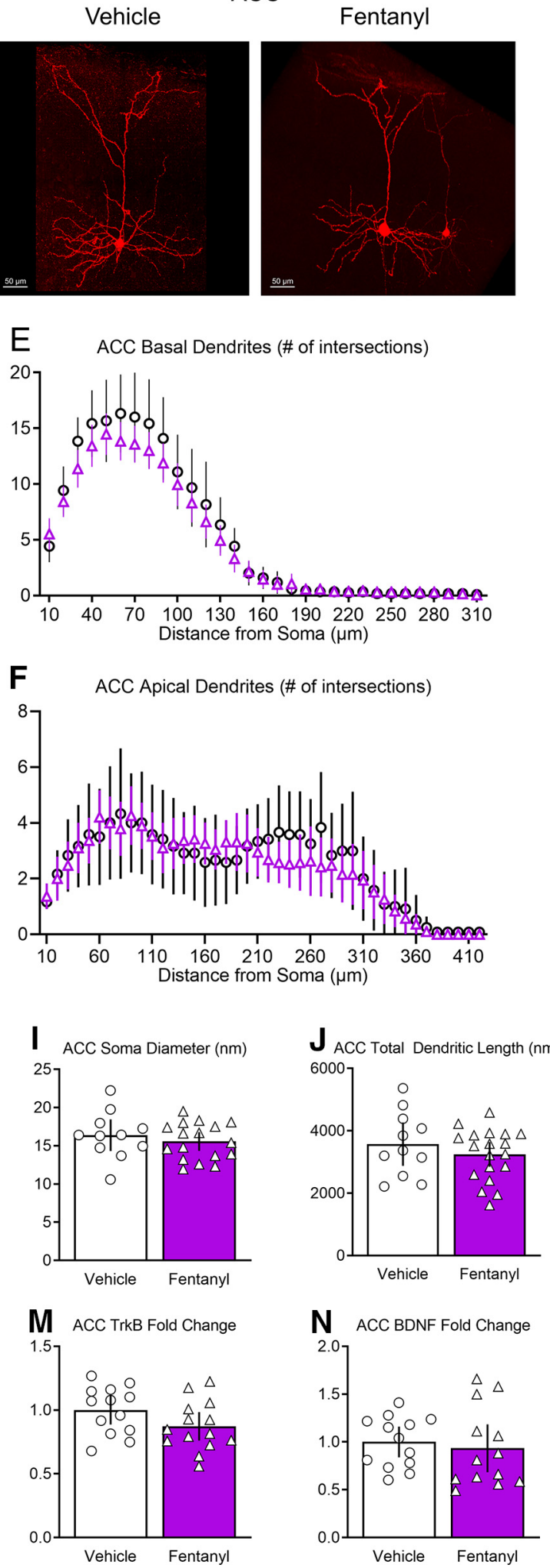

Figure 6. Perinatal fentanyl exposure reduces morphology of basal dendrites of pyramidal neurons in S1. A, Timeline depicting morphologic assays of pyramidal neurons. $\boldsymbol{B}$, Example of biocytin-filled layer 5 pyramidal neurons in $\mathrm{S} 1$ and ACC. Sholl analysis reveals that perinatal fentanyl exposure results in reduced branching of $\mathrm{S} 1$ basal $(\boldsymbol{C})$ but not apical dendrites $(\boldsymbol{D})$. There were no differences in branching of ACC basal $(\boldsymbol{E})$ or apical dendrites $(\boldsymbol{F})$. Fentanyl-exposed mice exhibited, in S1, decreased soma diameter $(\boldsymbol{G})$ and decreased total dendritic length $(\boldsymbol{H})$. Fentanyl- 
of $\mathrm{mGluR}_{8}$ was unexpected. These results suggest that decreased S1 excitatory transmission does not involve changes to $\mathrm{mGluR}_{8}$ mRNA expression.

In ACC, where we found a large decrease in presynaptic glutamate release, there was a large effect decrease mRNA expression of $\mathrm{mGluR}_{1}$ (unpaired $t$ test, $t_{(25)}=5.82, p<10^{-4}$, Cohen's $d=2.26$ ), but no difference in expression of $\mathrm{mGluR}_{5}$ (unpaired $t$ test, $t_{(25)}=1.23, p=0.22$ ). Among the group- 2 mGluRs, there was a large effect decrease expression of $\mathrm{mGluR}_{2}$ (unpaired $t$ test, $t_{(25)}=2.55, p=0.01$, Cohen's $d=0.98$ ), and $\mathrm{mGluR}_{3}$ (unpaired $t$ test, $t_{(25)}=2.13, p=0.04$, Cohen's $d=0.81$ ). There were no differences in group- 3 mGluRs: mGluR $_{4}$ (unpaired $t$ test, $t_{(25)}=1.45$, $p=0.15$ ), $\mathrm{mGluR}_{7}$ (unpaired $t$ test, $t_{(25)}=0.82, p=0.41$ ), or $\mathrm{mGluR}_{8}$ (unpaired $t$ test, $t_{(25)}=2.01, p=0.06$ ). The decreases in group-1 and group- 2 mGluRs are consistent with a reduction in presynaptic inhibition of glutamate release in ACC, and with our finding of increased excitatory transmission in this cortical area.

\section{AMPAR and NMDAR mRNA expression}

In S1, despite an absence of change in the amplitude of AMPAR currents, there was a large effect decrease in expression of GluR1 (unpaired $t$ test, $t_{(25)}=2.09, p=0.04$, Cohen's $d=0.79$; Table 1 ), and GluR3 (Mann-Whitney test, $U=48, p=0.03$, Glass' $\delta=1.06$ ). There was no difference in expression of GluR2 (Mann-Whitney test, $U=62, p=0.16$ ), or GluR4 (unpaired $t$ test, $\left.t_{(25)}=1.80, p=0.08\right)$. We found no change in the amplitude of AMAR currents in ACC. Consistent with this, there was no difference in expression of GluR1 (unpaired $t$ test, $t_{(25)}=1.05$, $p=0.30$ ), GluR2 (unpaired $t$ test, $t_{(25)}=0.05, p=0.95$ ), GluR3 (unpaired $t$ test, $t_{(25)}=1.96, p=0.06$ ), or GluR4 (unpaired $t$ test, $\left.t_{(25)}=0.09, p=0.92\right)$ in ACC of mice perinatally exposed to fentanyl compared with controls. That changes in the expression of GluR1 and GluR3 did not result in changes in AMPA responses in $\mathrm{S} 1$ might relate to the complex interactions and functions among these subunits (Diering and Huganir, 2018).

The reduction in NMDAR-mediated currents in S1 neurons suggests that expression of NMDARs was affected by perinatal fentanyl exposure. However, we found no difference in expression of GluN2A (unpaired $t$ test, $t_{(25)}=0.73, p=0.46$; Table 1), GluN2B (Mann-Whitney test, $U=84, p=0.75$ ), or GluN2D (unpaired $t$ test, $t_{(25)}=0.67, p=0.50$ ) in mice perinatally exposed to fentanyl compared with controls. We did find a large effect increase expression of GluN2C (Mann-Whitney test, $U=36$, $p=0.01$, Glass' $\delta=2.04$ ); however these subunits are primarily expressed in S1 astrocytes (Palygin et al., 2011; Ravikrishnan et al., 2018).

In ACC, where there was no change in NMDA currents, there was a large effect decreased expression of GluN2A (unpaired $t$ test, $t_{(25)}=2.52, p=0.01$, Cohen's $d=0.96$ ) and GluN2D (unpaired $t$ test, $t_{(24)}=6.17, p<10^{-4}$, Cohen's $d=2.42$ ). There was no difference in expression of GluN2B (unpaired $t$ test, $t_{(22)}=1.72, p=0.09$ ) or GluN2C (unpaired $t$ test, $t_{(25)}=0.83$, $p=0.41)$.

These results may reflect the limited sensitivity of our mRNA expression assay. It is important to note that other molecular

$\leftarrow$

exposed mice also had decreased mRNA expression of TrkB receptors $(\boldsymbol{K})$, with no difference in expression of BDNF $(\boldsymbol{L})$. In ACC, there were no differences in soma diameter $(\boldsymbol{I})$, total dendritic length $(\boldsymbol{J})$, mRNA expression of TrkB receptors $(\boldsymbol{M})$, or BDNF $(\boldsymbol{N})$. Data depict means for parametric or medians for non-parametric comparisons with $95 \%$ confidence intervals. $* p<0.05$. mechanisms may be affected by perinatal fentanyl exposure including receptor trafficking, expression of the receptor on the membrane, receptor affinity, or posttranslational changes in these subunits. Our expression data are consistent with previous reports showing that prenatal morphine exposure alters kinetic properties of NMDARs (Yang et al., 2000, 2003).

\section{Discussion}

We report that perinatal fentanyl exposure results in neurobiological deficits that last at least until adolescence. This exposure suppresses adaptation to sensory stimuli, impairs synaptic transmission in S1 and ACC, suppresses cortical oscillations, results in abnormal dendritic morphology of cortical pyramidal neurons, and alters mRNA expression of gene targets related to synaptic transmission and dendritic morphology.

\section{The model}

We confirm and expand on our previous description of a model of perinatal fentanyl exposure, in which dams are administered fentanyl in their drinking water (Alipio et al., 2020). The treatment extended from conception through weaning, to mimic the embryonic development period in humans (Chen et al., 2017). We expand on our previous findings by testing the effects of a range of fentanyl concentrations. Here, we find that this exposure has no effect on dam's health or maternal care behaviors, suggesting that the lasting effects we observe in perinatal fentanyl exposed adolescents reflects the direct actions of fentanyl during early development. Consistent with findings in humans, perinatal fentanyl exposure in mice results in smaller litters, higher newborn mortality rates, and signs of withdrawal shortly after birth. Thus, this model of perinatal opioid exposure has face validity for NOWS and for the lasting effects of this exposure.

\section{Cortical excitatory tone}

In S1 layer 5 neurons of adolescent mice, perinatal fentanyl exposure resulted in a reduction in synaptic excitation, and an increase in synaptic inhibition. The frequency of mEPSCs was increased and that of mIPSCs were decreased, consistent with changes in presynaptic release (Zucker and Regehr, 2002). The increase in the paired-pulse ratio of evoked EPSCs is consistent with reduced vesicle release from excitatory synapses. The amplitude of evoked excitatory synapses was decreased, due, in part, to a reduction in their NMDAR-mediated component.

In ACC layer 5 neurons of adolescent mice, perinatal fentanyl exposure enhanced excitatory synaptic transmission. Spontaneous excitatory vesicle release was enhanced, likely through a presynaptic mechanism. This presynaptic effect was mirrored in electrically evoked excitatory synaptic transmission. These findings are demonstrated by increases in the frequency of mEPSCs and depression of evoked paired pulse EPSCs.

Our findings are consistent with previous reports of long-lasting changes in neocortical and hippocampal synaptic activity and plasticity after prenatal exposure to morphine or heroin (Slotkin et al., 2003; Velísek et al., 2003; Yanai et al., 2003; Niu et al., 2009; Tan et al., 2015).

The changes in synaptic transmission in S1 and ACC were large and affected both male and female mice. For example, the frequency of mEPSC were 3-fold smaller in S1 and 2-fold larger in ACC than in controls. The NMDA/AMPA ratio was 2-fold smaller in S1. These findings indicate that the changes resulting from perinatal fentanyl exposure are physiologically salient. 
The contrasting changes in excitatory synaptic transmission in S1 and ACC may be because of differential expression of opioid receptors during cortical development. Opioid receptors are detectable in the central nervous system of mice as early as embryonic day (ED)11.5 and develop in the cortical subplate at ED15.5 (Zhu et al., 1998). This is around the same time of migration and differentiation of neurons in layer IV of S1 (Angevine and Sidman, 1961). ACC development does not begin until the last few days of gestation, with full lamination occurring around PD10 (Van Eden and Uylings, 1985). Activity at these opioid receptors during this critical period of development constrains growth and development of cortical neurons (Zagon and McLaughlin, 1987; Hammer et al., 1989; Ricalde and Hammer, 1990). Thus, the contrasting effects of perinatal fentanyl exposure on S1 and ACC might reflect the different maturational state of opioid systems in these areas at the time of fentanyl exposure.

\section{Morphologic changes}

The changes in synaptic functions were accompanied by abnormalities in basal dendrites of S1 layer 5 pyramidal neurons. Consistent with this finding, there was a decrease in mRNA expression of TrkB, which is involved in neuronal growth, development, and maturation (Klein et al., 1989). These findings are consistent with prior studies reporting that perinatal morphine exposure reduces dendritic growth and development of S1 pyramidal neurons by acting on opioid receptors during early development (Ricalde and Hammer, 1990; Maharajan et al., 2000; Mei et al., 2009). More recent studies reveal that chronic morphine administration reduces TrkB mRNA expression in D1-type medium spiny neurons within the nucleus accumbens (Koo et al., 2014).

\section{Neural oscillations}

Cortical oscillations, particularly in the $\gamma$ range, depend critically on the balance of inhibitory and excitatory synaptic activity (Buzsáki and Wang, 2012). Thus, we predicted that cortical oscillations will become disorganized by perinatal fentanyl exposure. Indeed, treated mice exhibited suppressed oscillations. These oscillations are related to large scale brain network activity and to cognitive phenomena, such as sensory processing, working memory, and attention (Lutz et al., 2004; Steriade, 2006; Buzsáki and Tingley, 2018). Perinatal exposure resulted also in decreased expression of the CB1R mRNA, consistent with reports of such decreases after morphine exposure (Rubino et al., 1997). A balance of excitatory and inhibitory transmission is reflected in $\gamma$ oscillations, that are regulated by CB1R activity (Holderith et al., 2011; Buzsáki and Wang, 2012), suggesting that these synaptic anomalies may be causally related to the oscillation abnormalities. The important role $\gamma$ oscillations in normal sensory processing and other cognitive tasks suggest that the abnormalities we observed may lead to the lasting deficits in sensory adaptation in mice treated perinatally with fentanyl (Mably and Colgin, 2018; Adaikkan and Tsai, 2020)

\section{Sensory adaptation}

A consequence of the constellation of circuit, network, and morphologic effects, reported here, of perinatal fentanyl exposure is compromised sensory adaptation. Here, we show that this exposure results in compromised adaptation to repeated tactile stimuli. Longitudinal clinical studies of children and adolescents exposed perinatally to opioids report cognitive, behavioral, and sensory deficits, as well as increased vulnerability to future stressors (Logan et al., 2013; Kivisto et al., 2015; Maguire et al., 2016;
Tobon et al., 2019). Impaired sensory processing is associated with attention deficit disorders, autism spectrum, schizophrenia, and synesthesia (Freedman et al., 1987; Lou et al., 1989; Leekam et al., 2007; van Leeuwen et al., 2020).

The synaptic and circuit sequelae of perinatal fentanyl exposure reported here suggest that these lasting behavioral deficits reflect specific and contrasting lasting changes in different cortical regions. Further studies of these changes may direct interventions to ameliorate or prevent these neuropsychiatric deficits.

\section{References}

Adaikkan C, Tsai LH (2020) Gamma entrainment: impact on neurocircuits, glia, and therapeutic opportunities. Trends Neurosci 43:24-41.

Alipio JB, Brockett AT, Fox ME, Tennyson SS, deBettencourt CA, ElMetwally D, Francis NA, Kanold PO, Lobo MK, Roesch MR, Keller A (2020) Enduring consequences of perinatal fentanyl exposure in mice. Addict Biol. Advance online publication. Retrieved March 18, 2020. doi: 10.1111/adb.12895.

Angevine JB, Sidman RL (1961) Autoradiographic study of cell migration during histogenesis of cerebral cortex in the mouse. Nature 192:766-768.

Ayres AJ (1964) Tactile functions. Their relation to hyperactive and perceptual motor behavior. Am J Occup Ther 18:6-11.

Bakhireva LN, Holbrook BD, Shrestha S, Leyva Y, Ashley M, Cano S, Lowe J, Stephen JM, Leeman L (2019) Association between prenatal opioid exposure, neonatal opioid withdrawal syndrome, and neurodevelopmental and behavioral outcomes at 5-8 months of age. Early Hum Dev 128:6976.

Balasco L, Provenzano G, Bozzi Y (2019) Sensory abnormalities in autism spectrum disorders: a focus on the tactile domain, from genetic mouse models to the clinic. Front Psychiatry 10:1016.

Bokil H, Andrews P, Kulkarni JE, Mehta S, Mitra PP (2010) Chronux: a platform for analyzing neural signals. J Neurosci Methods 192:146-151.

Brockett AT, Tennyson SS, deBettencourt CA, Gaye F, Roesch MR (2020) Anterior cingulate cortex is necessary for adaptation of action plans. Proc Natl Acad Sci USA 117:6196-6204.

Brogly SB, Saia KE, Werler MM, Regan E, Hernández-Díaz S (2018) Prenatal treatment and outcomes of women with opioid use disorder. Obstet Gynecol 132:916-922.

Buzsáki G, Wang XJ (2012) Mechanisms of gamma oscillations. Annu Rev Neurosci 35:203-225.

Buzsáki G, Tingley D (2018) Space and time: the hippocampus as a sequence generator. Trends Cogn Sci 22:853-869.

Chaplan SR, Bach FW, Pogrel JW, Chung JM, Yaksh TL (1994) Quantitative assessment of tactile allodynia in the rat paw. J Neurosci Methods 53:5563.

Chen VS, Morrison JP, Southwell MF, Foley JF, Bolon B, Elmore SA (2017) Histology atlas of the developing prenatal and postnatal mouse central nervous system, with emphasis on prenatal days E7.5 to E18.5. Toxicol Pathol 45:705-744.

Deuis JR, Dvorakova LS, Vetter I (2017) Methods used to evaluate pain behaviors in rodents. Front Mol Neurosci 10:284.

Diering GH, Huganir RL (2018) The AMPA receptor code of synaptic plasticity. Neuron 100:314-329.

Dixon WJ (1965) The up-and-down method for small samples. J Am Stat Assoc 60:967-978.

Ferraguti F, Klausberger T, Cobden P, Baude A, Roberts JD, Szucs P, Kinoshita A, Shigemoto R, Somogyi P, Dalezios Y (2005) Metabotropic glutamate receptor 8 -expressing nerve terminals target subsets of GABAergic neurons in the hippocampus. J Neurosci 25:10520-10536.

Fox K, Glazewski S, Schulze S (2000) Plasticity and stability of somatosensory maps in thalamus and cortex. Curr Opin Neurobiol 10:494-497.

Fox ME, Chandra R, Menken MS, Larkin EJ, Nam H, Engeln M, Francis TC, Lobo MK (2020) Dendritic remodeling of D1 neurons by RhoA/Rho-kinase mediates depression-like behavior. Mol Psychiatry 25:1022-1034.

Freedman R, Adler LE, Gerhardt GA, Waldo M, Baker N, Rose GM, Drebing C, Nagamoto H, Bickford-Wimer P, Franks R (1987) Neurobiological studies of sensory gating in schizophrenia. Schizophr Bull 13:669-678.

GBD 2016 Alcohol and Drug Use Collaborators (2018) The global burden of disease attributable to alcohol and drug use in 195 countries and 
territories, 1990-2016: a systematic analysis for the Global Burden of Disease Study 2016. Lancet Psychiatry 5:987-1012.

Haight SC, Ko JY, Tong VT, Bohm MK, Callaghan WM (2018) Opioid use disorder documented at delivery hospitalization - United States, 19992014. MMWR Morb Mortal Wkly Rep 67:845-849.

Hammer RP, Ricalde AA, Seatriz JV (1989) Effects of opiates on brain development. Neurotoxicology 10:475-483.

Holderith N, Németh B, Papp OI, Veres JM, Nagy GA, Hájos N (2011) Cannabinoids attenuate hippocampal $\gamma$ oscillations by suppressing excitatory synaptic input onto CA3 pyramidal neurons and fast spiking basket cells. J Physiol 589:4921-4934.

Honein MA, Boyle C, Redfield RR (2019) Public health surveillance of prenatal opioid exposure in mothers and infants. Pediatrics 143:e20183801.

Hug CC, Murphy MR (1981) Tissue redistribution of fentanyl and termination of its effects in rats. Anesthesiology 55:369-375.

Hunt RW, Tzioumi D, Collins E, Jeffery HE (2008) Adverse neurodevelopmental outcome of infants exposed to opiate in-utero. Early Hum Dev 84:29-35.

Jannetto PJ, Helander A, Garg U, Janis GC, Goldberger B, Ketha H (2019) The fentanyl epidemic and evolution of fentanyl analogs in the United States and the European Union. Clin Chem 65:242-253.

Kahila H, Gissler M, Sarkola T, Autti-Rämö I, Halmesmäki E (2010) Maternal welfare, morbidity and mortality 6-15 years after a pregnancy complicated by alcohol and substance abuse: a register-based case-control follow-up study of 524 women. Drug Alcohol Depend 111:215-221.

Kandall SR, Albin S, Dreyer E, Comstock M, Lowinson J (1975) Differential effects of heroin and methadone on birth weights. Addict Dis 2:347-355.

Kandall SR, Albin S, Lowinson J, Berle B, Eidelman AI, Gartner LM (1976) Differential effects of maternal heroin and methadone use on birthweight. Pediatrics 58:681-685.

Kennerley SW, Walton ME, Behrens TEJ, Buckley MJ, Rushworth MFS (2006) Optimal decision making and the anterior cingulate cortex. Nat Neurosci 9:940-947.

Kilroy E, Aziz-Zadeh L, Cermak S (2019) Ayres theories of autism and sensory integration revisited: what contemporary neuroscience has to say. Brain Sci 9:68

Kivisto K, Nevalainen P, Lauronen L, Tupola S, Pihko E, Kivitie-Kallio S (2015) Somatosensory and auditory processing in opioid-exposed newborns with neonatal abstinence syndrome: a magnetoencephalographic approach. J Matern Fetal Neonatal Med 28:2015-2019.

Klein R, Parada LF, Coulier F, Barbacid M (1989) trkB, a novel tyrosine protein kinase receptor expressed during mouse neural development. EMBO J 8:3701-3709.

Koo JW, Lobo MK, Chaudhury D, Labonté B, Friedman A, Heller E, Peña CJ, Han MH, Nestler EJ (2014) Loss of BDNF signaling in D1R-expressing NAc neurons enhances morphine reward by reducing GABA inhibition. Neuropsychopharmacology 39:2646-2653.

Lee SJ, Bora S, Austin NC, Westerman A, Henderson JMT (2020) Neurodevelopmental outcomes of children born to opioid-dependent mothers: a systematic review and meta-analysis. Acad Pediatr 20:308318.

Leekam SR, Nieto C, Libby SJ, Wing L, Gould J (2007) Describing the sensory abnormalities of children and adults with autism. J Autism Dev Disord 37:894-910.

Logan BA, Brown MS, Hayes MJ (2013) Neonatal abstinence syndrome: treatment and pediatric outcomes. Clin Obstet Gynecol 56:186-192.

Lomazzo E, König F, Abassi L, Jelinek R, Lutz B (2017) Chronic stress leads to epigenetic dysregulation in the neuropeptide-Y and cannabinoid CB1 receptor genes in the mouse cingulate cortex. Neuropharmacology 113:301-313.

Lou HC, Henriksen L, Bruhn P, Børner H, Nielsen JB (1989) Striatal dysfunction in attention deficit and hyperkinetic disorder. Arch Neurol 46:4852.

Lush ME, Ma L, Parada LF (2005) TrkB signaling regulates the developmental maturation of the somatosensory cortex. Int J Dev Neurosci 23:523536.

Lutz A, Greischar LL, Rawlings NB, Ricard M, Davidson RJ (2004) Longterm meditators self-induce high-amplitude gamma synchrony during mental practice. Proc Natl Acad Sci USA 101:16369-16373.

Mably AJ, Colgin LL (2018) Gamma oscillations in cognitive disorders. Curr Opin Neurobiol 52:182-187.
Maguire DJ, Taylor S, Armstrong K, Shaffer-Hudkins E, Germain AM, Brooks SS, Cline GJ, Clark L (2016) Long-term outcomes of infants with neonatal abstinence syndrome. Neonatal Netw 35:277-286.

Maharajan P, Prencipe R, Di Francesco P, Paino G, Ravagnan G, Maharajan V (2000) Maternal morphine alters parvalbumin immunoreactivity patterns in neonatal mouse brain. Synapse 35:265-271.

McPherson C, Haslam M, Pineda R, Rogers C, Neil JJ, Inder TE (2015) Brain injury and development in preterm infants exposed to fentanyl. Ann Pharmacother 49:1291-1297.

Meaney MJ (2001) Maternal care, gene expression, and the transmission of individual differences in stress reactivity across generations. Annu Rev Neurosci 24:1161-1192.

Mei B, Niu L, Cao B, Huang D, Zhou Y (2009) Prenatal morphine exposure alters the layer II/III pyramidal neurons morphology in lateral secondary visual cortex of juvenile rats. Synapse 63:1154-1161.

Mountcastle VB (1998) Perceptual neuroscience. Cambridge: Harvard University Press.

Niu L, Cao B, Zhu H, Mei B, Wang M, Yang Y, Zhou Y (2009) Impaired in vivo synaptic plasticity in dentate gyrus and spatial memory in juvenile rats induced by prenatal morphine exposure. Hippocampus 19:649-657.

O’Donnell JK, Halpin J, Mattson CL, Goldberger BA, Gladden RM (2017) Deaths involving fentanyl, fentanyl analogs, and U-47700 - 10 states, July-December 2016. MMWR Morb Mortal Wkly Rep 66:1197-1202.

Ornoy A (2003) The impact of intrauterine exposure versus postnatal environment in neurodevelopmental toxicity: long-term neurobehavioral studies in children at risk for developmental disorders. Toxicol Lett 140141:171-181.

Ornoy A, Segal J, Bar-Hamburger R, Greenbaum C (2001) Developmental outcome of school-age children born to mothers with heroin dependency: importance of environmental factors. Dev Med Child Neurol 43:668-675

Palygin O, Lalo U, Pankratov Y (2011) Distinct pharmacological and functional properties of NMDA receptors in mouse cortical astrocytes. Br J Pharmacol 163:1755-1766.

Raver SM, Keller A (2014) Permanent suppression of cortical oscillations in mice after adolescent exposure to cannabinoids: receptor mechanisms. Neuropharmacology 86:161-173.

Raver SM, Haughwout SP, Keller A (2013) Adolescent cannabinoid exposure permanently suppresses cortical oscillations in adult mice. Neuropsychopharmacology 38:2338-2347.

Ravikrishnan A, Gandhi PJ, Shelkar GP, Liu J, Pavuluri R, Dravid SM (2018) Region-specific expression of NMDA receptor GluN2C subunit in parvalbumin-positive neurons and astrocytes: analysis of GluN2C expression using a novel reporter model. Neuroscience 380:49-62.

Ricalde AA, Hammer RP (1990) Perinatal opiate treatment delays growth of cortical dendrites. Neurosci Lett 115:137-143.

Robertson CE, Baron-Cohen S (2017) Sensory perception in autism. Nat Rev Neurosci 18:671-684.

Rogers SJ, Ozonoff S (2005) Annotation: what do we know about sensory dysfunction in autism? A critical review of the empirical evidence. J Child Psychol Psychiatry 46:1255-1268.

Rubenstein E, Young JC, Croen LA, DiGuiseppi C, Dowling NF, Lee LC, Schieve L, Wiggins LD, Daniels J (2019) Brief report: maternal opioid prescription from preconception through pregnancy and the odds of autism spectrum disorder and autism features in children. J Autism Dev Disord 49:376-382.

Rubino T, Tizzoni L, Viganò D, Massi P, Parolaro D (1997) Modulation of rat brain cannabinoid receptors after chronic morphine treatment. Neuroreport 8:3219-3223.

Ryan SA (2018) Calculating the real costs of the opioid crisis. Pediatrics 141: e20174129.

Schulteis G, Heyser CJ, Koob GF (1999) Differential expression of responsedisruptive and somatic indices of opiate withdrawal during the initiation and development of opiate dependence. Behav Pharmacol 10:235-242.

Shigemoto R, Kinoshita A, Wada E, Nomura S, Ohishi H, Takada M, Flor PJ, Neki A, Abe T, Nakanishi S, Mizuno N (1997) Differential presynaptic localization of metabotropic glutamate receptor subtypes in the rat hippocampus. J Neurosci 17:7503-7522.

Slotkin TA, Seidler FJ, Yanai J (2003) Heroin neuroteratogenicity: delayedonset deficits in catecholaminergic synaptic activity. Brain Res 984:189197. 
Spencer MR, Warner M, Bastian BA, Trinidad JP, Hedegaard H (2019) Drug overdose deaths involving fentanyl, 2011-2016. Natl Vital Stat Rep 68:119

Steriade M (2006) Grouping of brain rhythms in corticothalamic systems. Neuroscience 137:1087-1106.

Sutter MB, Leeman L, Hsi A (2014) Neonatal opioid withdrawal syndrome. Obstet Gynecol Clin North Am 41:317-334.

Tan JW, Duan TT, Zhou QX, Ding ZY, Jing L, Cao J, Wang LP, Mao RR, Xu L (2015) Impaired contextual fear extinction and hippocampal synaptic plasticity in adult rats induced by prenatal morphine exposure. Addict Biol 20:652-662.

Ting JT, Daigle TL, Chen Q, Feng G (2014) Acute brain slice methods for adult and aging animals: application of targeted patch clamp analysis and optogenetics. Methods Mol Biol 1183:221-242.

Tobon AL, Habecker E, Forray A (2019) Opioid use in pregnancy. Curr Psychiatry Rep 21:118.

Van Eden CG, Uylings HB (1985) Postnatal volumetric development of the prefrontal cortex in the rat. J Comp Neurol 241:268-274.

van Leeuwen TM, Neufeld J, Hughes J, Ward J (2020) Synaesthesia and autism: different developmental outcomes from overlapping mechanisms. Cogn Neuropsychol 37:433-449.

Velísek L, Slamberová R, Vathy I (2003) Prenatal morphine exposure suppresses mineralocorticoid receptor-dependent basal synaptic transmission and synaptic plasticity in the lateral perforant path in adult male rats. Brain Res Bull 61:571-576.

Volpe DA, McMahon Tobin GA, Mellon RD, Katki AG, Parker RJ, Colatsky T, Kropp TJ, Verbois SL (2011) Uniform assessment and ranking of opioid $\mu$ receptor binding constants for selected opioid drugs. Regul Toxicol Pharmacol 59:385-390.

Wade CL, Schuster DJ, Domingo KM, Kitto KF, Fairbanks CA (2008) Supraspinally-administered agmatine attenuates the development of oral fentanyl self-administration. Eur J Pharmacol 587:135-140.

Weaver ICG, Cervoni N, Champagne FA, D'Alessio AC, Sharma S, Seckl JR, Dymov S, Szyf M, Meaney MJ (2004) Epigenetic programming by maternal behavior. Nat Neurosci 7:847-854.
Whiteman VE, Salemi JL, Mogos MF, Cain MA, Aliyu MH, Salihu HM (2014) Maternal opioid drug use during pregnancy and its impact on perinatal morbidity, mortality, and the costs of medical care in the United States. J Pregnancy 2014:906723.

Wilson GS, McCreary R, Kean J, Baxter JC (1979) The development of preschool children of heroin-addicted mothers: a controlled study. Pediatrics 63:135-141.

Winkelman TNA, Villapiano N, Kozhimannil KB, Davis MM, Patrick SW (2018) Incidence and costs of neonatal abstinence syndrome among infants with Medicaid: 2004-2014. Pediatrics 141:e20173520.

Yanai J, Huleihel R, Izrael M, Metsuyanim S, Shahak H, Vatury O, Yaniv SP (2003) Functional changes after prenatal opiate exposure related to opiate receptors' regulated alterations in cholinergic innervation. Int J Neuropsychopharmacol 6:253-265.

Yang SN, Yang JM, Wu JN, Kao YH, Hsieh WY, Chao CC, Tao PL (2000) Prenatal exposure to morphine alters kinetic properties of NMDA receptor-mediated synaptic currents in the hippocampus of rat offspring. Hippocampus 10:654-662.

Yang SN, Huang LT, Wang CL, Chen WF, Yang CH, Lin SZ, Lai MC, Chen SJ, Tao PL (2003) Prenatal administration of morphine decreases CREBSerine-133 phosphorylation and synaptic plasticity range mediated by glutamatergic transmission in the hippocampal CA1 area of cognitivedeficient rat offspring. Hippocampus 13:915-921.

Yeh ML, Selvam R, Levine ES (2017) BDNF-induced endocannabinoid release modulates neocortical glutamatergic neurotransmission. Synapse 71:e21962.

Zagon IS, McLaughlin PJ (1987) Endogenous opioid systems regulate cell proliferation in the developing rat brain. Brain Res 412:68-72.

Zhu Y, Hsu MS, Pintar JE (1998) Developmental expression of the mu, kappa, and delta opioid receptor mRNAs in mouse. J Neurosci 18:25382549.

Zucker RS, Regehr WG (2002) Short-term synaptic plasticity. Annu Rev Physiol 64:355-405. 